\title{
Arabidopsis inositol polyphosphate kinases IPK1 and ITPK1 modulate crosstalks between SA-dependent immunity and phosphate-starvation responses
}

Hitika Gulabani $^{1,2, \#}$, Krishnendu Goswami ${ }^{1 \#}$, Yashika Walia ${ }^{1}$, Jewel Jameeta Noor ${ }^{1,}$, Kishor D. Ingole $^{1,3}$, Abhisha Roy ${ }^{1}$, Debabrata Laha ${ }^{4}$, Gabriel Schaaf ${ }^{5}$, and Saikat Bhattacharjee ${ }^{1 *}$

${ }^{1}$ Laboratory of Signal Transduction and Plant Resistance, UNESCO-Regional Centre for Biotechnology (RCB), NCR Biotech Science Cluster, $3^{\text {rd }}$ Milestone, Faridabad-Gurgaon Expressway, Faridabad- 121001, Haryana, India.

${ }^{2}$ Manipal Academy of Higher Education (MAHE), Manipal University, Manipal - 576104, Karnataka, India.

${ }^{3}$ Kalinga Institute of Industrial Technology (KIIT) University, Bhubaneswar- 751024, Odisha, India.

${ }^{4}$ Department of Biochemistry, Indian Institute of Science, Bengaluru, Karnataka- 560012 , India.

${ }^{5}$ Department of Plant Nutrition, Institute of Crop Science and Resource Conservation, Rheinische Friedrich-Wilhelms-Universität Bonn, 53115 Bonn, Germany.

\# Equal contributions

Keywords: Inositol polyphosphates, Arabidopsis thaliana, basal immunity, PstDC3000, salicylic acid, phosphate-starvation response

\section{Word count: 7578}

\section{ORCID ID}

Saikat Bhattacharjee https://orcid.org/0000-0003-1369-7700

Gabriel Schaaf https://orcid.org/0000-0001-9022-4515 
Hitika Gulabani https://orcid.org/0000-0001-7234-4556

Krishnendu Goswami https://orcid.org/0000-0002-6549-0130

Yashika Walia https://orcid.org/0000-0001-8122-8661

Jewel Jameeta Noor https://orcid.org/0000-0002-5971-8004

Kishor D Ingole https://orcid.org/0000-0003-1946-6639

Abhisha Roy https://orcid.org/0000-0003-1946-6639

Debabrata Laha https://orcid.org/0000-0002-3431-0811

\section{Abstract}

The propensity for polyphosphorylation makes myo-inositol derivatives, the inositol polyphosphates (InsPs), especially phytic acid or inositol hexakisphosphate ( $\left.\operatorname{InsP}_{6}\right)$ the major form of phosphate storage in plants. Acts of pyrophosphorylation on $\operatorname{InsP}_{6}$ generates $\operatorname{Ins}_{7}$ or Ins $\mathrm{P}_{8}$ containing high-energy phosphoanhydride bonds that are harnessed during energy requirements of a cell. Also implicated as co-factors for several phytohormone signaling networks, $\mathrm{InsP}_{7} / \mathrm{Ins}_{8}$ modulate key developmental processes. With recent identification as the common moeity for transducing both jasmonic acid (JA) and phosphate-starvation responses (PSR), InsP $\mathrm{P}_{8}$ is the classic example of a metabolite that may moonlight crosstalks to different cellular pathways during diverse stress adaptations. We show here that Arabidopsis thaliana INOSITOL PENTAKISPHOSPHATE 2-KINASE (IPK1), INOSITOL $\quad$ 1,3,4TRISPHOSPHATE 5/6-KINASE 1 (ITPK1), and DIPHOSPHOINOSITOL PENTAKISPHOSPHATE KINASE 2 (VIH2), but not other InsP-kinases, suppress basal salicylic acid (SA)-dependent immunity. In ipk1, itpkl or vih2 mutants, elevated endogenous SA levels and constitutive activation of defense signaling lead to enhanced resistance against the virulent Pseudomonas syringae pv tomato DC3000 (PstDC3000) strain. Our data reveal that activated SA-signaling sectors in these mutants modulate expression amplitudes of 
phosphate-starvation inducible (PSI)-genes, reported earlier. In turn, via mutualism the heightened basal defenses in these mutants require upregulated PSI-gene expressions likely highlighting the increased demand of phosphates required to support immunity. We demonstrate that SA is induced in phosphate-deprived plants, however its defense-promoting functions are likely diverted to PSR-supportive roles. Overall, our investigations reveal selective InsPs as crosstalk mediators among diverse signaling networks programming stressappropriate adaptations.

\section{INTRODUCTION}

Several evidences illustrate the versatility and relevance of inositol (Ins) derivatives in regulating cellular homeostasis in plants (Majerus, 1992; Murthy, 1996; Gillaspy, 2011; Gillaspy, 2013). The availability of six hydroxyl groups on a cyclic alcohol and its propensity to attach varied number of phosphates generates diverse water soluble InsP moieties with roles in cellular transduction of signals in multiple pathways (Shears et al., 2012). Evidentially, tight regulations in maintaining cellular ratios of different InsPs are crucial and disturbed only spatiotemporally during cellular responses (Monserrate and York, 2010; Mishkind et al., 2009). As a potent chelator of polyvalent metal ions especially $\mathrm{Ca}^{2+}, \mathrm{Mg}^{2+}, \mathrm{Zn}^{2+}, \mathrm{Fe}^{2+}$ among others, although $\mathrm{InsP}_{6}$ is considered an anti-nutrient, recent studies identify anti-oxidative benefits of these roles in therapeutic interventions (Silva and Bracarense, 2016). The phospholipid conjugates phosphatidylinositols (PtdIns) though comprise only a minor pool of membrane lipids nevertheless is pivotal in determining cell architectures, facilitate protein anchors, regulate vesicle trafficking, organizes cytoskeleton, and also serve as sources for signaling InsPs via the lipid-dependent pathway (Munnik and Nielsen, 2011; Boss and Im, 2012). Dynamic changes in localized PtdIns are orchestrated by phosphatases and 
phospholipases and are key players in downstream signaling during regular development or responses to (a)biotic stresses (Dieck et al., 2012; Heilmann, 2016).

Glucose-6-phosphate, the precursor molecule for InsP biosynthesis is converted to myoinositol-3-phosphate (Ins3P) by MYO-INOSITOL PHOSPHATE SYNTHASES (MIPS1-3 in Arabidopsis) (Donahue et al., 2010). Subsequent dephosphorylation of Ins3P by INOSITOL MONOPHOSPHATASE (IMP) generates myo-inositol (Ins) for conjugation with phospholipids via membrane-localized PHOSPHATIDYLINOSITOL SYNTHASE (PIS). Ins is phosphorylated by PtdIns4-KINASE (PI4K) and PtdIns4P 5-KINASES (PIP5K) for PtdIns4P and PtdIns(4,5) $\mathrm{P}_{2}$ synthesis. Biotic or abiotic stimuli cause activation of PHOSPHOLIPASE C (PLC) that hydrolyzes PtdIns4P or PtdIns(4,5) $\mathrm{P}_{2}$ producing diacylglycerol (DAG) and inositol trisphosphate $\left(\operatorname{InsP}_{3}\right)$ that have important roles as signaling transducers of downstream responses (Gillaspy, 2011; Hong et al., 2016). InsP $\mathrm{P}_{3}$ causes increase in intracellular calcium $\left(\mathrm{Ca}^{2+}\right)$ via its liberation from endogenous stores although a bona fide receptor for $\mathrm{InsP}_{3}$-gated calcium release remains unidentified in plants (Berridge, 1993; Lee et al., 1996; Gillaspy, 2011; Boss and Im, 2012). Increasing studies indicate that instead of being the direct mediator of intracellular $\mathrm{Ca}^{2+}$ spike, in plants as well as in yeast, $\mathrm{InsP}_{3}$ is converted primarily to $\operatorname{InsP}_{6}$ for this function. In response to drought stress or $\mathrm{ABA}$ treatment, $\operatorname{Ins}_{3}$ as well as $\mathrm{InsP}_{6}$ levels in guard cells are elevated causing stomatal closure (Lee et al., 1996; Staxen et al., 1999; Lemtiri-Chlieh et al., 2003). Controlled release of $\mathrm{InsP}_{3}$ or $\mathrm{InsP}_{6}$ from their respective caged-conjugates coincides with mobilization of $\mathrm{Ca}^{2+}$ from endomembrane reserves (Lemtiri-Chlieh et al., 2003). Again, the identity of the receptor that facilitates Ins $_{6}$-mediated $\mathrm{Ca}^{2+}$ spike remains elusive.

In the lipid-dependent origin of $\operatorname{Ins}_{6}$, sequential phosphorylation of $\mathrm{InsP}_{3}$ are performed by the redundant INOSITOL POLYPHOSPHATE 6-/3-KINASES (IPK2 $\alpha$ and IPK2 $\beta$ ) producing inositol tetrakisphosphate $\left(\mathrm{InsP}_{4}\right)$ and inositol-pentakisphosphate $\left(\operatorname{InsP}_{5}\right)$ (Xia et al., 2003; 
Stevenson-Paulik et al., 2005). An alternate lipid-independent pathway performing de novo synthesis of InsPs exists unique to plants and closely related protists (Stevenson-Paulik et al., 2005; Desfougeres et al., 2019). In this mode, via coordinated activities of myo-INOSITOL KINASE (MIK) and INOSITOL-TETRAKISPHOSPHATE 5,6-KINASES (ITPKs), InsP is sequentially phosphorylated to generate $\mathrm{InsP}_{5}$ (Shi et al., 2005). In Arabidopsis, a single geneencoded INOSITOL PENTAKISPHOSPHATE 2-KINASE (IPK1) catalyzes the synthesis of

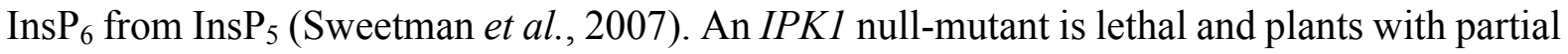
loss-of-function (ipk1-1) display developmental defects indicating the importance of this abundant InsP (Kuo et al., 2014). Low $\mathrm{InsP}_{6}$ plants are categorized as lpa (low phytic acid) and include ipk2 $\beta-1$, mrp5, itpk1-2, itpk4-1, and mik-1 (Stevenson-Paulik et al., 2005; Kim and Tai, 2011). Anti-nutrient property of $\mathrm{InsP}_{6}$ in humans and monogastric animals along with its negative impact as an environmental pollutant due to eutrophication has instigated continuous agricultural efforts to develop lpa crops (Turner et al., 2002). However, with noted developmental consequences in several lpa mutants such endeavors are a constant concern to overall plant health (Lee et al., 2015; Donahue et al., 2010). $\mathrm{InsP}_{6}$ is a further substrate for pyrophosphorylation by ITPK1/2 to generate $\mathrm{InsP}_{7}$ (Adepoju et al., 2019; Laha et al., 2019) and further to $\mathrm{InsP}_{8}$ by VIH1/2 kinases (Desai et al., 2014; Laha et al., 2015). During the last decade, co-factor roles of specific plant InsPs have gained prominence. Demonstrated by structural and mutational studies, $\mathrm{InsP}_{6} / \mathrm{InsP}_{7}$ role as cofactor in auxin-responses and $\mathrm{Ins}_{5} / \mathrm{InsP}_{8}$ for jasmonic-acid signaling have been deciphered (Tan et al., 2007; Sheard et al., 2010; Laha et al., 2015; Laha et al., 2020). More recently, $\operatorname{InsP}_{8}$ is also implicated in maintenance of Pi-homeostasis and regulates PSR (phosphate-starvation response) upon Pideprivation (Kuo et al., 2014; Kuo et al., 2018; Ried et al., 2019; Zhu et al., 2019; Dong et al., 2019). 
Incorporating such functional diversities in cellular processes, InsP implications on innate immune signaling of plants is undoubtedly apparent. In the two-layered defense signaling mechanisms, extracellular pattern-recognition receptors (PRRs) recognize conserved pathogen-associated molecular patterns (PAMPs) such as flagellin, chitin, or lipopolysaccharides and form the first line of basal defenses, also known as PAMP-triggered immunity (PTI) (Jones and Dangl, 2006; Schwessinger and Ronald, 2012). Elicitation of PTI leads to rapid increase in intracellular $\mathrm{Ca}^{2+}$, production of reactive oxygen species (ROS) and requires the defensive hormone salicylic acid (SA) to transduce the activation of downstream defense-associated genes such as FLG22-INDUCED RECEPTOR LIKE KINASE 1 (FRK1), WALL-ASSOCIATED KINASE 2 (WAK2), and PATHOGENESIS-ASSOCIATED PROTEINS (PR1, PR2) (Seybold et al., 2014; Bigeard et al., 2015; Sardar et al., 2017). Treatment of Arabidopsis suspension cells with SA decreases cellular pools of PtdIns with parallel increase in PtdIns4K and PtdIns(4,5) $\mathrm{P}_{2}$ levels (Krinke et al., 2007). Likewise, elicitation of PTI during PstDC3000 exposure causes elevated $\mathrm{InsP}_{3}$ in Arabidopsis seedlings (Hung et al., 2014). Murphy et al (2008) reported the essentiality of $\operatorname{Ins}_{6}$ in maintaining basal defence against various pathogens. In their assays, ipk1-1 and mips 2 , but not mips 1 , plants were compromised in PTI to PstDC3000 (Murphy et al., 2008). Defenses against the cyst nematode is also reduced in the ipk1-1 plants (Jain, 2015). Recently, it was shown that while ipk1-1 plants remain deficient in induction of local resistance, PTI hallmarks such as intracellular $\mathrm{Ca}^{2+}$ spike, ROS production, and upregulated expression of responsive markers remained comparable to wildtype plants (Poon et al., 2020). An earlier study though contrastingly claimed that induction of PTI markers upon PAMP-treatment are deficient in ipk1-1 (Ma et al., 2017). In the second immune layer, plants deploy intracellular nucleotide-binding leucine-rich repeat (NB-LRR) also known as resistance $(\mathrm{R})$ proteins to sense activities of secreted effectors that attempt to thwart PTI. These recognitions lead to effector-triggered immunity (ETI) consisting mostly of 
PTI patterns but with stronger amplifications (Thomma et al., 2011; Cui et al., 2015). Effectors that trigger ETI are known as avirulent. AvrRpm1 or AvrRpt2, two Pseudomonas avirulent effectors cause PLC-dependent accumulation of phosphatidic acid (PA) in the presence of the cognate R genes $R P M 1$ or $R P S 2$, respectively. As a further processed product of DAG, PA potentiates immune signaling (Andersson et al., 2006). While from the above studies it is increasingly obvious that InsP derivatives are vital for immune processes, their contributions or individual specificities are not known.

Here, we utilized several Arabidopsis InsP-biosynthesis/metabolism mutants to test their defensive potentials against the virulent PstDC3000 strain. Primarily, among the InsP-kinase mutants investigated, we identify the role of IPK1, ITPK1 and VIH2 as suppressors of SAdependent immunity. Constitutive activation of SA-dependent defenses confers enhanced basal immunity to ipk1-1, itpk1-2 or vih2-4 plants, and is abolished when the SA-signaling networks are disrupted. With comparative InsP profiling we reveal possible link between low $\mathrm{InsP}_{8}$, in these mutants to their elevated defenses. Together with the recently implicated roles of the above InsP-kinases in phosphate homeostasis, we demonstrate its intersection on SA-based immunity. Overall, through genetic and molecular evidences we reveal unique coordination between phosphate and defense signaling pathways highlighting responsive balances of a plant during stress adaptations.

\section{RESULTS}

\section{IPK1, ITPK1 and VIH2 are suppressors of basal immunity against PstDC3000}

Previously, it was reported that $\mathrm{InsP}_{6}$ is essential for promoting PTI and ETI in Arabidopsis (Murphy et al., 2008). The ipk1-1 plants displayed deficient defenses against virulent and avirulent PstDC3000 strains although neither basal SA nor its upregulation upon PAMP- 
treatment was affected thus suggesting immune compromises in processes downstream of SA (Murphy et al., 2008; Poon et al., 2020). Because ipk1-1 plants are also depleted for $\mathrm{InsP}_{7}$ and $\mathrm{InsP}_{8}$, whereas $\mathrm{InsP}_{4}$ accumulates (Stevenson-Paulik et al., 2005; Laha et al., 2015), their contributions to altered defense outcome remained uninvestigated. In order to gain deeper insights into this, we screened a series of InsP mutants for basal defenses against virulent PstDC3000. We chose T-DNA insertional mutants of myo-INOSITOL KINASE (MIK) (mik1)(Kim and Tai, 2011), INOSITOL 1,4,5-TRISPHOSPHATE KINASES (IPK2 $\alpha$ and IPK2 $\beta$ )

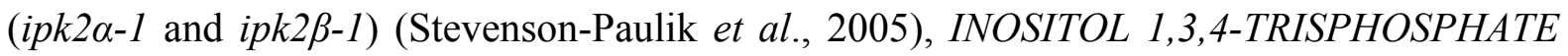
5/6-KINASES (ITPK1,3,4) (itpk1-2, itpk3-1, itpk4-1) (Wilson and Majerus, 1997; Sweetman et al., 2007; Kim and Tai, 2011; Laha et al., 2020), and DIPHOSPHOINOSITOL PENTAKISPHOSPHATE KINASES (VIH1,2) (vih1-1, vih2-4) (Laha et al., 2015). The ipk1-1 plants were used as a comparative control. To note, among these mutants, mik-1,ipk1-1, ipk $2 \beta$ 1, itpk1-2 and itpk4-1 are designated lpa mutants (Stevenson-Paulik et al., 2005; Kim and Tai, 2011). Seeds were obtained from Arabidopsis stock centre or as a gift and confirmed via genotyping PCR to identify homozygous insertions for the corresponding T-DNAs. In our growth regime, ipkl-1 and itpkl-2 plants displayed contrasting growth retardation phenotype with leaf epinasty (Figure 1a) as previously described (Stevenson-Paulik et al., 2005; Kuo et al., 2014; Kuo et al., 2018). These phenotypic defects were more pronounced under long-day (LD) conditions of growth. In the respective complemented lines ipk1-1:Myc-IPK1 (Walia et al., 2020) or itpk1-2:ITPK1-GFP (Laha et al., 2020), growth defects were abolished and the transgenic plants were indistinguishable to Col-0 (Figure 1a; Figure S1). Further, constitutive expression of phosphate-starvation-inducible (PSI) genes and resulting elevated Pi accumulations previously known for ipkl-1 or itpkl-2 (Kuo et al., 2014; Kuo et al., 2018) were also restored to Col-0 levels in the complemented lines (Figure S2a) (Laha et al., 2020; Walia 
bioRxiv preprint doi: https://doi.org/10.1101/2021.01.27.428180; this version posted January 28,2021 . The copyright holder for this preprint (which was not certified by peer review) is the author/funder, who has granted bioRxiv a license to display the preprint in perpetuity. It is made available under aCC-BY-ND 4.0 International license.

et al., 2020). Overall, these results validated the corresponding T-DNA mutational consequences on the abnormal growth phenotypes and constitutive PSR in ipkl-1 or itpkl-2.

When challenged with the virulent PstDC3000, we noted a clear decrease in bacterial accumulations in ipk1-1, itpk1-2 and vih2-4, but not other InsP-kinase mutants, amounting to reductions by $\sim 5-10$ fold compared to Col- 0 (Figure $1 \mathrm{~b}$ ). Whereas elevated basal immunity in itpkl-2 and vih2-4 were not known before, enhanced resistance of ipkl-1 we observed in our assays in particular contradicts its increased susceptibility reported earlier (Murphy et al., 2008; Poon et al., 2020).

\section{Basal elevations in SA-based defenses associate with ipk1-1, itpk1-2 and vih2-4 plants}

The above contrasting results led us to further investigate whether defense-associated features linked to enhanced basal immunity are represented in the above InsP-kinase mutants. As SA is key mediator of these defenses, we measured the relative transcript levels of SALICYLIC ACID-DEFICIENT 2/ ISOCHORISMATE SYNTHASE 1 (SID2/ICS1), the enzyme performing defense-induced SA biosynthesis (Nawrath and Métraux, 1999). In ipk1-1 or itpk1-2, but not their respective complemented lines, and also in the vih2-4 plants strong upregulation in SID2/ICS1 expressions relative to Col-0 were noted (Figure 1c; Figure S3a). Further, free or glucosyl moiety-conjugated SA (SAG) levels were higher in ipk1-1, itpk1-2 or vih2-4 extracts relative to Col-0 (Figure 1d; Figure S3e). These observations were at discrepancy with the earlier report (Murphy et al., 2008) showing that basal SA levels or its induction post-avirulent PstDC3000 infection remains comparable between Col-0 and ipk1-1. Regardless, SA or SAG enhancements were restored to Col-0 levels in the respective complemented lines of ipk1-1 or itpkl-2 affirming that the SA elevations are indeed attributed to the corresponding ipkl-1 or itpkl-2 mutations. 
Elevated SA induces $P R 1$ or $P R 2$ expressions. In ipk1-1, itpk1-2 or vih2-4 plants, prominent increase in $P R 1 / P R 2$ expressions with parallel accumulation of respective proteins in comparison to Col-0 were observed (Figure 2a,b; Figure S3). Endogenous levels of several PAMP-responsive genes such as FRK1, WAK2, FOX, CYP81F2, or WRKY38 (Sardar et al., 2017) were also elevated in these mutants relative to Col-0 (Figure S3; Figure S4a,b). NONEXPRESSOR of PATHOGENESIS-RELATED 1 (NPR1) orchestrates the induction of SAresponsive genes including PRI (Cao et al., 1997; Zhang et al., 1999). We detected clear enhancement in NPR1 protein levels in ipk1-1 or itpk1-2 than Col-0 (Figure 2c). This was in accordance to increased NPR1 accumulation upon SA-analog 2,6-dichloroisonicotinic acid (INA) treatments reported earlier for Col-0 (Kinkema et al., 2000). Basal defenses require ENHANCED DISEASE SUSCEPTIBILITY 1 (EDS1) and an eds1 mutant (eds1-2) is hypersusceptible to virulent PstDC3000 (Feys et al., 2001). Notably, in several auto-immune mutants EDS1 or the R protein SUPPRESSOR OF npr1-1 CONSTITUTIVE 1 (SNC1) accumulations are increased due to elevated SA responses (Garcia et al., 2010; Li et al., 2010; Dnyaneshwar Ingole et al., 2020). Distinct increase in EDS1 and SNC1 protein levels were observed in ipk1-1 or itpkl-2 compared to Col-0 (Figure 2d,e). As again, extracts from complemented lines restored EDS1 elevations to Col-0 levels. Further, increased callose deposits also signify induced basal defenses in auto-immune plants (Dnyaneshwar Ingole et al., 2020; Voigt, 2014). In ipk1-1 or itpk1-2, endogenous callose accumulations were significantly higher than Col-0 providing further validation to their increased basal immunity we observed (Figure 2f). Taken together, our results convincingly illustrate auto-immune phenotypes of ipk1-1, itpk1-2 and vih2-4.

\section{SA-signaling routes are responsible for enhanced basal immunity in ipk1-1 or itpk1-2}

To genetically associate enhanced SA-regulated networks to heightened basal defenses in ipkl1 or itpk1-2, we generated ipk1-1 eds1-2, ipk1-1 sid2-1, itpk1-2 eds1-2 and itpk1-2 sid2-1 
double mutants. An eds1-2 plant has truncation in the EDS1 gene rendering it non-functional whereas the sid2-1 harbors a null-mutation in SID2/ICS1 (Wildermuth et al., 2001, Cui et al., 2017). Loss of either EDS1 or SID2/ICS1 did not affect the growth retardation phenotypes of ipk1-1 or itpk1-2 implying that these defects are SA-independent (Figure 3a). Nonetheless, eds1-2 and more prominently sid2-1 mutation in ipk1-1 or itpk1-2 reduced the elevated PRI expressions (Figure 3b). Taking into account that EDS1 mediates positive amplification loop of SA-based defense signaling, residual PRI levels that remain elevated in ipkl-1 eds1-2 or itpk1-2 eds1-2 are likely indicative of this. Likewise, FRK1 expression enhancements in ipk11 was abolished by sid2-1 but only modestly affected by eds $1-2$ (Figure S4c,d). Upon challenge with PstDC3000, ipk1-1 eds1-2, ipk1-1 sid2-1, itpk1-2 eds1-2 or itpk1-2 sid2-1 plants lost enhanced basal immunity and instead were as hypersusceptible as eds1-2 or sid2-1 plants (Figure 3c). The results thus implied that primed defenses in ipk1-1 and itpk1-2 were indeed routed through SA-signaling networks. For additional support, we also generated ipk1-1 nprl1 double mutants. As observed earlier for ipk1-1 eds 1-2 or ipk1-2 sid2-1 plants, growth defects of ipkl-1 remained unchanged in ipk1-1 nprl-1 reemphasizing that processes that are SAindependent likely cause the developmental deficiencies (Figure S5a). Loss of NPR1 resulted in substantial down-regulation of $P R 1 / P R 2$ transcript elevations in ipk1-1 (Figure S5b). Overall, these evidences provide strong indications of IPKI and ITPKI functions as suppressors of SA-mediated immunity.

\section{Reduced InsP $P_{8}$ may contribute to elevated defences of ipk1-1 and itpk1-2}

Primarily, IPK1 and ITPK1 activities constitute a metabolic pair that coordinates synthesis of $\mathrm{Ins}_{7}$ from $\mathrm{InsP}_{5}$ (Laha et al., 2019; Adepoju et al., 2019; Whitfield et al., 2020). Ins $\mathrm{P}_{7}$ is further pyrophosphorylated by $\mathrm{VIH} 1 / 2$ to produce $\mathrm{InsP}_{8}$ (Laha et al., 2015). Along with reduced $\mathrm{Ins}_{7}$ in $i p k 1-1$ or $i t p k 1-2, \mathrm{InsP}_{8}$ levels are also lower in these mutants similar to vih24 (Stevenson-Paulik et al., 2005; Laha et al., 2015; Kuo et al., 2018). The vih2-4 plants 
however have basal levels of $\operatorname{InsP}_{6}$ but elevated $\operatorname{InsP}_{7}$ (Laha et al., 2015). In itpk4-1, low Ins $\mathrm{P}_{6}$ have been recently reported but levels of $\mathrm{InsP}_{7}$ in these plants remain contrasting between two published studies (Kuo et al., 2018; Laha et al., 2020). Total InsP profiles of mik-1 or ipk2 $\beta-1$ especially in context of $\mathrm{InsP}_{7}$ or $\mathrm{InsP}_{8}$ is not known. In order to determine which InsPs contribute towards enhanced SA-dependent immunity, we performed SAX-HPLC analyses of $\left[{ }^{3} \mathrm{H}\right]$-inositol-labelled seedlings of Col-0, mik-1, and ipk2 $\beta-1$. We also included ipk1-1, itpk12 and itpk4-1 in these measurements. Although Ins $\mathrm{P}_{6}$ levels were reduced in mik-1 or ipk $2 \beta-1$ seedlings, $\mathrm{InsP}_{7}$ or $\mathrm{InsP}_{8}$ levels were unchanged from Col-0 (Figure 3d and Figure S6). From these analysis, we surmised a possible correlation between specific InsP and altered defenses. Reduced $\mathrm{InsP}_{6}$ is not likely the cause of enhanced basal immunity since mik-1,ipk2 $\beta-1$ or itpk41 display Col-0-comparable defenses. Neither the decreased $\operatorname{Ins}_{7}$ is a cause for the same since itpk4-1 with claimed deficiency in this InsP (Kuo et al., 2018) does not show altered defensive capabilities against PstDC3000. Increased $\mathrm{InsP}_{7}$ levels in vih2-4 also does not result in enhanced susceptibility, as would be expected from this hypothesis. Taken together, by exclusion it is suggestive that low $\mathrm{InsP}_{8}$ common to ipk1-1, itpk1-2 and vih2-4 may be linked to their enhanced basal immunity. Interestingly, InsP separation profile of ipkl-1eds 1-2 mirrored ipk1-1 patterns indicating that increased SA-based defenses were downstream consequences to the altered InsPs (Figure 3d).

\section{Constitutive PSR augments enhanced SA-defenses in ipk1-1 and itpk1-2}

Constitutive activation of PSI-genes is characteristic of ipk1-1 or itpkl-2 (Kuo et al., 2014; Kuo et al., 2018). Under sufficient phosphate conditions, the transcription factor PHOSPHATE STARVATION RESPONSE 1 (PHR1) is sequestered by SPX1 (SYG1/Pho81/XPR1-domain containing protein 1) in the presence of $\mathrm{InsP}_{8}$ cofactor (Puga et al., 2014; Zhong et al., 2018). This prevents its binding to promoters of PSI-genes and activating PSR. When soil Pi is low, 
phosphatase activity of VIH2 is activated resulting in reduced $\operatorname{InsP}_{8}$, liberating PHR1 and causing 26S proteasome mediated degradation of SPX1 (Zhu et al., 2019, Ried et al., 2019). In a breakthrough report, PHR1 was shown to suppress several SA-responsive gene expressions (Castrillo et al., 2017). Arabidopsis phrl phll double mutant (PHL1 is a paralogue of PHR1) is enhanced resistant to PstDC3000. While reduced $\mathrm{InsP}_{8}$ likely activates PHR1/PHL1 functions in ipk1-1 or itpk1-2, increased SA-dependent immunity in these plants appear as a contradiction. To determine whether constitutive PSR influences enhanced SAresponses of ipkl-1 or itpk1-2, we obtained ipk1-1 phrl phll (Kuo et al., 2018) and generated itpkl-2 phrl phll triple mutants by genetic crossing of phrl phll double mutant with itpkl-2. A phrl phl1 double mutant is defective in PSR induction and basal levels of Pi are lower than Col-0 (Bustos et al., 2010; Kuo et al., 2014). We observed that growth defects of ipk1-1 or itpkl-2 are not recovered in ipk1-1 phrl phll or itpkl-2 phrl phll, respectively suggesting that these phenotypes are independent of PHR1/PHL1 (Figure 4a). Further, as expected increased endogenous Pi levels in ipk1-1 or itpk1-2 and elevated expression of PSI-genes IPS1 or SPXI are reduced below Col-0 levels in the above triple mutants (Figure S2a,b) (Kuo et al., 2014).

To determine whether abolishment of enhanced PSR by the loss of PHR1/PHL1 affected basal accumulation of $P R 1 / P R 2$ transcripts, we compared their relative expression levels between the respective triple and the single InsP-kinase mutants. In accordance with the enhanced defenses against PstDC3000 infection reported earlier (Castrillo et al., 2017), both PR1 and PR2 expressions were slightly but not significantly elevated in phrl phll plants when compared to Col-0 (Figure 4b). Surprisingly, introducing phrl phll mutation in ipk1-1 or itpkl2 substantially reduced the upregulated $P R 1 / P R 2$ expressions (Figure $4 \mathrm{~b}$ ). These results suggested that elevated PSR associated with PHR1/PHL1 activities contributes positively to the enhanced defense-gene expressions in the above InsP-kinase mutants.

\section{Elevated SA in ipk1-1 or itpk1-2 aggravate PSR via feedback mode}


Several PSI-genes have SA-inducible elements in their promoters (Baek et al., 2017). Therefore, to determine whether elevated SA reciprocates on PSR in ipkl-1 and itpk1-2, we investigated for changes in endogenous Pi elevations in ipk1-1 sid2-1 and itpk1-2 sid2-1 plants. Loss of SID2/ICS1 or EDS1 toned-down elevated Pi levels in ipk1-1 or itpk1-2 (Figure 4c). When compared for relative expression of PSI-genes, $S P X 1$ or the transcription factor $W R K Y 38$ displayed reduced expressions in itpk1-2 sid2-1 or ipk1-1 sid2-1, respectively compared to the itpk1-2 or ipk1-1 parent (Figure 4d). Likewise, ipk1-1 npr1-1 plants also contained lower endogenous Pi-levels than ipk1-1, and displayed complete or partial restoration of WRKY38 or an another PSR-marker SAL2 (3'(2'), 5'-bisphosphate nucleotidase/inositol polyphosphate 1phosphatase) (Gil-Mascarell et al., 1999) expressions, respectively to Col-0 levels (Figure S5d). Interestingly, it is known that WRKY38 is SA-inducible and requires NPR1 for transcriptional activation (Kim et al., 2008). With these results, it is suggestive that heightened SA-signaling sectors aggravate but are not the direct cause of PSR in ipk1-1 or itpk1-2.

To further substantiate the SA-promotion on PSI-gene expression, we treated Col-0 with SA and measured the kinetics of $S P X 1$ or $W R K Y 38$ transcripts. Remarkably, SA exposure progressively increased $S P X 1$ or $W R K Y 38$ expressions from 30-120 min post-treatment (mpt)

(Figure 5a). The kinetics closely matched those of $P R 1$ inductions in the same samples. These data therefore corroborated that indeed SA can potentiate PSR in plants by directly activating the transcription of at least a subset of PSI-genes.

\section{PSR reprogrammes defense-signaling networks of SA}

In phrl phll plants, a significant proportion of differentially expressed genes are SA-inducible (Castrillo et al., 2017). These include immune-associated genes that possess P1BS (PHR1binding site) elements and therefore are direct PHR1-targets. If indeed SA is augmenting PSR as we noted in ipkl-1 or itpkl-2 plants, it is possible that its defensive roles are re-routed to 
support PSR processes. To investigate this, we subjected Col-0 plants to Pi-starvation and measured the basal levels of SA and expression of downstream PR1, FRK1, or NPR1 genes. Under Pi-deprivation, SA or SAG levels were significantly elevated and restored rapidly when exogenously supplemented with phosphate in the growth medium (Figure 5b). Most surprisingly, even with SA-elevations, expression of PRI or FRK1 was downregulated upon Pi-starvation supporting suppression of basal immunity as proposed earlier (Figure 5c) (Castrillo et al., 2017). WRKY38 is a known negative regulator of basal immunity (Kim et al., 2008). Endogenous $P R 1$ expression levels are higher in wrky38-1 plants and result in enhanced immunity to PstDC3000. Thus, with these into consideration it is implicative that although PSR induces SA, its roles are diverted from immune promotion to PSR supportive functions possibly involving WRKY38.

\section{PHR1-dependent induction of PSI-genes affect intensity of PTI responses}

Implications on positive influence of SA on expression of PSI-genes, prompted us to determine whether in a physiological context of a pathogen threat a similar phenomenon is observed. Towards this, Col-0 or phrl plants were challenged with PstDC3000 as earlier and hallmarks of PSR responses tested in the infected tissues. As is expected, expression of SID2/ICS1 and PRI was induced in Col-0 at 3-dpi (Figure 6a,b). Curiously, these upregulations in the phrl plants were significantly lower than Col-0. Whereas SID2/ICS1 or PR1 transcripts showed $>10$-fold increase in Col-0, these were only $\sim 6$-fold elevated in phrl plants post-infection. Further, while expression of PSI-genes PHT3;2 or PAP17 demonstrated clear upregulations with PstDC3000 exposure on Col-0, their induction in $\mathrm{phrl}$ plants were comparatively lower (Figure 6c,d). Likely, functional PHL1 in phrl plants accounted for the residual elevation. Not the least, we surprisingly noted clear increase in endogenous Pi levels in Col-0 upon PstDC3000 infection suggesting that PTI elicitation is accompanied by changes in Pihomeostasis possibly through induced PSR pathway (Figure 6e). Indeed, in phrl plants this 
increase was barely detected suggesting that these responses are primarily PHR1-orchestrated. We recently reported that IPK1 and ITPK1 protein stabilities are increased during PSR perhaps signifying their intersection on diverse signaling pathways (Walia et al., 2020). Likewise, upon PstDC3000 challenge on ipk1-1:Myc-IPK1 or itpk1-2:ITPK1-GFP plants we noted improvements in IPK1 and ITPK1 protein stabilities likely reflective of a similar phenomenon (Figure 6f). With these results, we reveal regulated synergism between basal defenses and phosphate homeostasis incorporating roles of selective InsP-kinases, IPK1 and ITPK1. Overall, with our investigations here we identify intricacies of signaling crosstalks, modulations, and re-adjustments during stress adaptations.

\section{DISCUSSION}

Plant immune responses recruit complex signaling networks and intricate interplay of phytohormone activities. While these remains tightly orchestrated and transitory under normal physiological threats to avoid fitness costs, the same is not always apparent in several characterized autoimmune mutants. With the pleiotropic phenotypes displayed by these mutants the complexity of crosstalks that occur among different signaling pathways and the players/signals that mediate these are increasingly being unraveled (van Wersch et al., 2016). Our study here especially highlights the selective involvement of two InsP-kinases IPK1 and ITPK1 in SA-dependent regulation of innate immune signaling. With previously established roles in maintaining Pi-homeostasis (Kuo et al., 2014; Kuo et al., 2018), JA (Sheard et al., 2010; Mosblech et al., 2011; Boss \& Im, 2012), and auxin signaling (Tan et al., 2007; Laha et $a l ., 2020)$ we demonstrate their repercussions on SA-mediated basal defenses. Both ipk1-1 and itpk1-2 plants, similar to vih2-4, display enhanced immunity to virulent PstDC3000. The common $\mathrm{InsP}_{7} / \mathrm{InsP}_{8}$ reduction in these mutants posits that perturbations leading to their 
enhanced immunity may be attributed to multiple factors. Suppression of SA-driven pathway by the loss of either SID2/ICS1 or EDS1 mitigates the enhanced resistance in ipk1-1 or itpk1-2 plants implying that the immune disturbances are likely upstream of SA-biosynthesis as evidenced by increased expression of SID2/ICSI in these mutants relative to Col-0.

It is evident that our results present contradictions to earlier reports claiming the essentiality of InsP $_{6}$ in maintaining basal defenses against PstDC3000 (Murphy et al., 2008; Ma et al., 2017; Poon et al., 2020). First, with the extensive list of InsP-kinase mutants we tested in our pathogenesis assays, we are unable to correlate reduced $\mathrm{InsP}_{6}$ levels to altered basal immunity. Especially mik-1, ipk2 $\beta-1$ or itpk4-1 have lower cellular $\operatorname{InsP}_{6}$ pools but display Col-0comparable PTI. While we confirm that $\mathrm{InsP}_{6}$ is reduced in ipkl-1 as earlier (Murphy et al., 2008; Kuo et al., 2018), for itpk1-2 we mirror Laha et al (2020) that phytic acid levels remains unchanged. Nevertheless, even after considering these InsP discrepancies, only ipk1-1 and itpk1-2 have elevated basal immunity in our assays. Therefore, as implied earlier perhaps $\operatorname{Ins}_{6}$ changes at specific cellular locale(s) and not globally per se may primarily affect basal immunity. We describe a possible scenario in the later section that may be in accordance with this hypothesis. Second, we detect prominent increase in endogenous SA levels causing elevated expression of PR1/PR2, several PTI markers, EDS1, SNC1 or NPR1 proteins in ipk11 or itpk1-2 plants. These upregulations are restored to Col-0 levels in the respective complemented lines thus providing support to our observations. Murphy et al (2008) however did not find noticeable change either in the basal SA levels or its increase upon avirulent pathogen challenge in ipk1-1. Further, although Poon et al (2020) did not measure the endogenous expression levels of FRK1 or other PTI markers, their induction upon PAMPtreatment was not affected in ipk1-1. Ma et al (2017) in contrast showed impaired induction of FRK1 and other PTI responses in ipk1-1 (also in mips1 and mips2) with PAMP-exposure. These increasing disparities between studies clearly raise considerable doubts of $\operatorname{InsP}_{6}$ role in 
basal immunity. Perhaps consorting factors such as growth regimen, soil compositions, light, temperature or humidity regulations impact the immunity in ipkl-1 making the responses conditional.

The vih2-4 plants have wild-type $\operatorname{InsP}_{6}$, although $\operatorname{InsP}_{7}$ or $\operatorname{Ins}_{8}$ levels are elevated or reduced, respectively (Laha et al., 2015). The hyper-defensive nature of vih2-4 plants we observe may hold a possible clue to relate specific InsP changes to basal immune enhancements. That, ipkl1 or itpk1-2, but not other InsP mutants we tested here, share $\mathrm{InsP}_{8}$ deficiency to vih2-4 (Laha et al., 2020) lends support our speculations. Antagonism between JA-SA crosstalks are well known and exploited intensely by both pathogens and plant hosts in their efforts to colonize or resist, respectively (Caarls et al., 2015). Coronatine, secreted by $P$. syringae pathovars is a JAanalog and attempts to suppress SA-mediated defenses by upregulating JA-responses (Zheng et al., 2012). NPR1 in turn is essential for inhibiting the expression of JA-responsive genes (Spoel et al., 2009). With $\mathrm{InsP}_{8}$ requirement as a cofactor vih2-4 plants therefore are compromised in JA-mediated defenses and remain hypersusceptible to herbivory (Laha et al., 2015). Elevated expression of PTI-responsive genes/SA levels in vih2-4 and likewise in ipk11 or itpk1-2 may hence be due to impaired JA signaling resulting in elevated SA-defenses. The observations from Poon et al (2020) that prior injection of air/water in ipkl-1 enhances resistance to PstDC3000 may be the result of JA-deficiencies causing SA-based immune elevations. Mosbelch et al (2011) data that ipk1-1 plants are JA-hypersensitive and resist Plutella xylostella caterpillar feeding however argues against this interpretation. Increased basal immunity in ipk1-1 or itpk1-2 may alternatively be attributed to reduced $\mathrm{Ins}_{7}$ levels and through a different mechanism than JA-antagonism. As the recently refined cofactor for auxin signaling, $\mathrm{InsP}_{7}$ facilitates TRANSPORT INHIBITOR RESPONSE 1 (TIR1)-mediated degradation of AUX/IAA repressors (Laha et al., 2020). Considering exogenous application of auxin potentiates PstDC3000 colonization by interfering with SA defenses (Navarro et al., 
2006; Wang et al., 2007), auxin-signaling impairments may conversely enhance basal immunity. Indeed, the auxin-insensitive mutant axr2-1 significantly reduces bacterial growth in SA-impaired NahG plants (Wang et al., 2007). Thus, a different mode of impairment in ipk1-1 or itpk1-2 than vih2-4 may be the cause of similar consequence of upregulated SAmediated defenses.

Under Pi-deplete conditions plant immunity is compromised for successful colonization of phosphate-remobilizing microbiota to enhance phosphate availability in soil for uptake (Castrillo et al., 2017). The upregulation of SA-inducible genes in PSR-deficient phrl phl1 plants suggests antagonism between PSR and SA responses. However, a more complex interplay we reveal here is likely deployed in the actual physiological responses to $\mathrm{Pi}$ deprivation. We show that constitutive PSR is partly responsible for aggravating SA-dependent immunity in ipk1-1 or itpkl-2. Loss of PHR1/PHL1 from ipk1-1 or itpkl-2 in addition to alleviating the enhanced PSR/Pi levels also tones down PR1/PR2 upregulations. Reciprocally, sid2-1 or eds 1-2 mutations that abrogate SA-mediated defenses partially mitigate constitutive PSR in ipk1-1 or itpk1-2. As predicted recently, several PSI-genes including SPX1 harbor SAresponsive elements (Baek et al., 2017) and may utilize the SA elevations we observe during PSR for optimal expression. That exogenous SA induces $S P X 1$ and $W R K Y 38$ expressions supports our claim. Interestingly, $W R K Y 38$, a negative regulator of basal immunity, is SAinducible and requires NPR1 (Kim et al., 2008). Phosphite, salt-conjugates of phosphorous acid $\left(\left[\mathrm{HPO}_{3}\right]^{2-}\right)$ used routinely as a fungicide, primes SA-dependent immunity and suppresses expression of PSI-genes (Varadarajan et al., 2002; Achary et al., 2017).

Upregulated expression of several PSI-genes upon a pathogen challenge we demonstrate here possibly highlights the energy necessities of defense, a process to which PSR-promoted Piuptake may significantly contribute. Multiple studies indeed report significant increase in ATP/ADP ratio (also known as adenylate charge status) during increased phosphate uptake 
post Pi-starvation (Zhu et al., 2019; Riemer et al., 2020). Activities of IPK1-ITPK1 pair and VIHs especially are modulated by changes in adenylate charge in a cell (Zhu et al., 2019; Riemer et al., 2020; Whitfield et al., 2020). Taken together these results suggest a mutual modulatory loop between SA and PSR networks involving specific InsPs. In Pi-starved wildtype plants immune suppressions are possibly accomplished by blocking SA-transduction of immunity by involving PHRl functions as a negative regulator of defensive-associated genes (Castrillo et al., 2017). Induced SA are channeled via NPR1-dependent roles into processes such as $W R K Y 38$ or $S P X 1$ expressions that promote PSR, simultaneously maintaining immune gene inhibitions. With possible dysfunctions in this coordination further aided by reduced $\operatorname{Ins}_{8}$ levels (or changes in other unidentified InsPs), ipk1-1 or itpk1-2 hence show constitutive PSR accompanied with elevated SA responses. The autoimmune siz1-2 plants that exhibit constitutive SA and PSR responses may exemplify another cellular module that intersects on PSR-SA harmony (Miura et al., 2011).

With the above, it is encouraging to consider that a common protein hub regulated by IPK1/ITPK1 activities orchestrate the fine-tuning of cellular signaling logistics upon a stimulus. We recently in a remarkable parallel with earlier animal studies identified that IPK1ITPK1 via strict locale-specific roles moderates the functioning of CONSTITUTIVE PHOTOMORPHOGENESIS 9 (COP9 also known as CSN) signalosome (Walia et al., 2020). We showed that CSN activities in turn maintain cellular Pi-homeostasis by regulating the Cullin RING Ligases (CRLs) functioning in targeted-degradation of substrates by the 26S proteasome complex. Functional deficiencies in CSN result in strong pleiotropic effects including auxin-insensitivity (Dohmann et al., 2008), constitutive activation of PSR (Walia et al., 2020), and impaired JA-defenses accompanied by elevated PR1 transcripts (Hind et al., 2011), thus revealing strong parallel with ipk1-1 or itpk1-2 defects. Rice SPX4, SNC1 or NPR1 stabilities are monitored by CRL functions placing molecular implications of IPK1/ITPK1 on 
bioRxiv preprint doi: https://doi.org/10.1101/2021.01.27.428180; this version posted January 28,2021 . The copyright holder for this preprint (which was not certified by peer review) is the author/funder, who has granted bioRxiv a license to display the preprint in perpetuity. It is made available under aCC-BY-ND 4.0 International license.

defense outcomes via CSN-CRL dynamics (Gou et al., 2012; Ruan et al., 2019; Ried et al., 2019; Shen et al., 2020). These indications lead us to advocate that between the investigated InsP-kinases, IPK1 and ITPK1 have acquired unique localized roles that impinge on central cellular machineries impacting multiple signaling networks. In conclusion, with our studies here we decipher complexities of plant signaling that recruits seemingly antagonistic networks and reassigns roles to specific players to elicit stimulus-appropriate response outputs.

\section{Material and Methods}

\section{Plant material and growth conditions}

Most T-DNA insertional mutants of Arabidopsis thaliana (accession Col-0) for the investigated InsP-kinases were obtained from Arabidopsis Biological Resource Centre (ABRC; www.abrc.osu.edu). The details of ipk1-1, itpk1-2, ipk2 $\beta-1$, itpk4-1, vih1-1, vih2-4 have been described earlier (Stevenson-Paulik et al., 2005; Kim and Tai, 2011; Kuo et al., 2014; Laha et al., 2015; Kuo et al., 2018; Laha et al., 2020). Primers used in genotyping for homozygous T-DNA insertions are listed in Supplementary Table 1. Seeds were cold-stratified for 2-days in dark, surface sterilized with $30 \%$ bleach, washed with three rinses of sterile water and then germinated on $0.5 \mathrm{x}$ Murashige and Skoog (MS) plus 1\% sucrose containing agar plates. Growth chambers were maintained at $24^{\circ} \mathrm{C}$ with $70 \% \mathrm{RH}$ and long-day (LD) conditions (16hrs:8hrs; light: dark cycle) with light intensity $100 \mu \mathrm{mol} \mu \mathrm{m}^{-2} \mathrm{~s}^{-1}$.

For Pi-starvation assays, plants grown on media plates as above were transferred 7-days postgermination to liquid MS medium in 12-well sterile culture plates containing either $625 \mu \mathrm{M}$ (Pi-sufficient) or $10 \mu \mathrm{M}$ (Pi-deficient) $\mathrm{KH}_{2} \mathrm{PO}_{4}$ for 4 days before being used for indicated assays. 
bioRxiv preprint doi: https://doi.org/10.1101/2021.01.27.428180; this version posted January 28,2021 . The copyright holder for this preprint (which was not certified by peer review) is the author/funder, who has granted bioRxiv a license to display the preprint in perpetuity. It is made available under aCC-BY-ND 4.0 International license.

\section{Generation of combinatorial mutants}

To generate ipk1-1 eds1-2, itpk1-2 eds1-2, ipk1-1 sid2-1, itpk1-2 sid2-1, ipk1-1 npr1-1 or itpk12 phrl phll combinatorial mutants, ipk1-1 or itpk1-2 were genetically crossed with eds $1-2$ (Cui et al., 2017), sid2-1 (Wildermuth et al., 2001), npr1-1 (Ramírez et al., 2010), or phr1 phl1 (Kuo et al., 2014) plants. Required combination of mutations and their homozygosity was determined by genomic PCRs of segregating plants either in the F2 or F3 populations. Primers for the same are listed in Supplementary Table 1.

\section{In planta PstDC3000 growth assays}

Bacterial growth assays for PstDC3000 were performed as earlier (Bhattacharjee et al., 2011). In brief, leaves from indicated plants soil-grown for 3-4 weeks were infiltrated with PstDC3000 strain at a bacterial density of $5 \times 10^{4} \mathrm{cfu} / \mathrm{ml}$ using a needleless syringe. Bacterial accumulation was measured at 0 and 3 days post-infiltration (dpi) by harvesting leaf discs of defined diameter, macerating in $10 \mathrm{mM} \mathrm{MgCl}_{2}$, and plating serial dilutions on Pseudomonas agar plates containing with $25 \mu \mathrm{g} / \mathrm{ml}$ Rifampicin. Growth of bacteria in the infiltrated leaves are reported as $\log _{10} \mathrm{cfu} / \mathrm{cm}^{2}$. For qPCRs and Pi estimation, a bacterial inoculum of $10^{6} \mathrm{cfu} / \mathrm{ml}$ was used. Tissues were harvested before and after infiltration ( 3 dpi) and processed accordingly.

\section{Salicylic acid (SA) measurements or treatments}

Free and glucose-conjugated SA were measured according to (DeFraia et al., 2008) employing the Acinetobacter sp. ADPWH_lux biosensor system. Extracts from sid2-1 plants spiked with known amounts of SA was used to generate standard curve. Luminescence was measured in a POLARStar Omega Luminometer (BMG Labtech). Data presented here are mean $( \pm \mathrm{SD})$ of three biological replicates. 
To determine induction of PSI genes, Col-0 plants grown on soil for 3-4 weeks were spraytreated with $0.5 \mathrm{mM} \mathrm{SA}$ (Sigma-Aldrich) and tissues harvested at indicated time-points for further analysis.

\section{RNA extraction, cDNA synthesis and qRT-PCR analysis}

Total RNA was extracted with RNAiso Plus (Takara) and cDNA synthesized with iScript cDNA Synthesis Kit (Bio-Rad) following manufacturer's instructions. Primers used for qRTPCR primers are listed in Supplementary Table 1. All qRT-PCRs were performed in QuantStudio 6 Flex Real-Time PCR system (Applied Biosystems) with 5X HOT FIREPol® EvaGreen ${ }^{\circledR}$ qPCR Mix Plus (ROX) (Solis BioDyne) according to the manufacturer's instructions. Each experiment contained three biological and technical replicates $(n=3)$. Arabidopsis MON1 (At2g28390) expression was used as internal control (Bhattacharjee et al., 2011). Relative expression was calculated according to the PCR efficiency^${ }^{\wedge} \Delta \Delta C$ t formula. Expressions were normalized relative to levels in Col-0 and plotted as fold-change.

\section{Protein extraction and western blots}

For immunoblotting, leaf tissues from indicated plants were homogenized in $6 \mathrm{M}$ Urea, clarified by centrifugation at $16,000 \mathrm{rpm}$ at $4^{\circ} \mathrm{C}$, mixed with $2 \times$ Laemmli buffer $(0.1 \mathrm{M}$ Tris $\mathrm{pH}$ 6.8, 20\% w/v glycerol, 4\% w/v SDS, $100 \mathrm{mM} \mathrm{DTT}$ and $0.001 \% \mathrm{w} / \mathrm{v}$ Bromophenol blue), separated on SDS-PAGE and transferred onto polyvinylidene fluoride (PVDF) membrane. Blocking was performed with $5 \% \mathrm{w} / \mathrm{v}$ non-fat skimmed milk powder in $1 \times$ TBST (TrisBuffered Saline, $0.1 \% \mathrm{w} / \mathrm{v}$ Tween ${ }^{\circledR} 20$ Detergent) for $1 \mathrm{hr}$, rinsed and incubated overnight at $4^{\circ} \mathrm{C}$ with indicated primary antibodies [anti-SNC1 (Abiocode; R3588-1), anti-PR1, anti-PR2, anti-NPR1 or anti-EDS1 (Agrisera; AS10687, AS122366, AS121854, AS132751, respectively)]. The membranes were washed the next day with three rinses of TBST, incubated at RT for $1 \mathrm{hr}$ with secondary antibodies conjugated with horseradish peroxidase (HRP) (Santa 
bioRxiv preprint doi: https://doi.org/10.1101/2021.01.27.428180; this version posted January 28,2021 . The copyright holder for this preprint (which was not certified by peer review) is the author/funder, who has granted bioRxiv a license to display the preprint in perpetuity. It is made available under aCC-BY-ND 4.0 International license.

Cruz Biotech). Rinsed membranes were then treated with ECL Prime solution (GE Healthcare) and luminescence imaged with an ImageQuant LAS 4000 system (GE Healthcare).

\section{Callose deposition assay}

Callose staining was performed according to (Schenk and Schikora, 2015). Callose spots were observed under a Nikon fluorescence microscope equipped with a camera using a DAPI filter and UV light.

\section{Extraction of InsPs and SAX-HPLC profiling}

Profiling of InsPs from indicated InsP-kinase mutants (and Col-0) were performed as according to (Laha et al., 2020). Briefly, Arabidopsis seedlings germinated for 10-days in 0.5x MS sucrose agar plates were transferred to liquid media containing $30 \mu \mathrm{Ci} \mathrm{mL}-1$ of $\left[{ }^{3} \mathrm{H}\right]-\mathrm{myo}-$ inositol (30 to $80 \mathrm{Ci} \mathrm{mmol-1;} \mathrm{Biotrend)} \mathrm{for} 6$ days. Seedlings were then rinsed with sterile water and flash-frozen with liquid $\mathrm{N}_{2}$. InsP extraction methodology was as described earlier (Azevedo and Saiardi, 2006). Extracts were then resolved by strong anion exchange high performance liquid chromatography (SAX-HPLC) using a Partisphere SAX 4.6 x 125 mm column (Whatman).

\section{Phosphate (Pi)-estimation assay}

Total Pi measurements in the indicated plants were performed according to (Chiou et al., 2006). Plant tissues frozen with liquid $\mathrm{N}_{2}$ were homogenized in extraction buffer (10 mM Tris- $\mathrm{HCl}$, $1 \mathrm{mM}$ EDTA, $100 \mathrm{mM} \mathrm{NaCl}, 1 \mathrm{mM}$ PMSF), mixed with 1\% glacial acetic acid (ratio 1:9 v/v) and then incubated at $42^{\circ} \mathrm{C}$ for 30 mins. To the reaction, Pi-assay solution $\left(0.35 \% \mathrm{NH}_{4} \mathrm{MoO}_{4}\right.$, $0.86 \mathrm{~N} \mathrm{H}_{2} \mathrm{SO}_{4}$ and $1.4 \%$ ascorbic acid) was added in a ratio of $3: 7(\mathrm{v} / \mathrm{v})$ and further incubated at $42^{\circ} \mathrm{C}$ for 30 mins. Absorbance was measured at $280 \mathrm{~nm}$ using a spectrophotometer. Standard graph was made with known amounts of $\mathrm{KH}_{2} \mathrm{PO}_{4}$ and total Pi content in the plant extracts calculated accordingly. 


\section{Acknowledgements}

All authors deeply acknowledge Regional Centre for Biotechnology (RCB), Faridabad for core-grant support, lab infrastructure, and central instrumental facilities. This study was supported by funds from DBT-Ramalingaswami Re-Entry Fellowship and Grant (No. BT/PR23666/AGIII/103/1039/2018) awarded to SB. The phrl phl1 double mutant seeds were a kind gift from Prof. Tzyy-Jen Chiou, Academia Sinica, Taipei. Prof. Ashis Kumar Nandi, Jawaharlal Nehru University (JNU), India provided the $n p r 1-1$ seeds. D.L. acknowledges the Indian Institute of Science, India for start-up funds.

\section{Author Contributions}

SB conceived the research. $\mathrm{HG}, \mathrm{KG}, \mathrm{JJN}, \mathrm{YW}$, and SB designed the experiments. HG, SB, $\mathrm{KG}$, and $\mathrm{KDI}$ performed mutant identification via genotyping. $\mathrm{HG}, \mathrm{KG}, \mathrm{KDI}, \mathrm{YW}$, and $\mathrm{AR}$ performed pathogen growth assays and qPCRs. JJN, KDI, and YW performed protein detections analysis. DL and GS generated the InsP profiles in the mutants. YW and SB wrote the manuscript.

\section{Data availability statement}

The data that supports the findings of this study are available in the supplementary material of this article

\section{Figure legends}




\section{FIGURE 1 Selective Arabidopsis InsP-kinase mutants display enhanced basal}

defenses against PstDC3000. (a) Growth phenotypes of 3 week-old Col-0, ipk1-1, itpk1-2, and the corresponding complemented lines ipk1-1:Myc-IPK1 and itpk1-2:ITPK1-GFP. (b) PstDC3000 infection assays. Leaves from indicated mutants and Col-0 plants were infiltrated with bacterial suspension at a density of $5 \times 10^{4} \mathrm{cfu} / \mathrm{ml}$. Bacterial inoculum in the infiltrated leaves (Day 0) and its growth (Day 3) were quantified on media plates containing appropriate antibiotics. (c) Relative expression of SID2/ICS1 in the indicated plants. Total RNA was isolated from leaves of 3-4 plants, reverse transcribed, and qRT-PCRs performed. Expressions were normalized to MON1. (d) Endogenous levels of free SA and total SA+SAG in the indicated plants. SA estimations were performed on 3-4 week-old plants. Data presented are mean $( \pm \mathrm{SD})$ of three biological and technical replicates. Statistical analysis is according to Student's $t$-test $(* * p<0.001, * * * p<0.0001, \mathrm{~ns}=$ not significant $)$.

\section{FIGURE 2 Expression of defense-associated genes/proteins are upregulated in ipk1-1}

or itpk1-2 plants. (a) Relative expression of $P R 1$ or $P R 2$ transcripts. qRT-PCRs were performed and normalized to MON1 gene-expressions as an internal control. Values are mean $\pm \mathrm{SD}$ with 3 biological and technical replicates $(\mathrm{n}=3)$. Student's $t$-test analysis is shown $\left(*^{* *} p<0.0001, \mathrm{~ns}=\right.$ not significant). Immunoblots of defense-associated proteins (b) PR1 or PR2, (c) NPR1, (d) EDS1, or (e) R protein SNC1 in indicated plants. Total proteins were probed with respective antibodies. The membrane was stained with Ponceau $\mathrm{S}$ to demonstrate comparable protein loadings. (f) Callose deposits on Col-0, ipk1-1, or itpk1-2 leaves. Fully expanded leaves from 3-week-old plants were stained for callose and observed under a fluorescence microscope. Scale bar $=50 \mu \mathrm{m}$. 
bioRxiv preprint doi: https://doi.org/10.1101/2021.01.27.428180; this version posted January 28,2021 . The copyright holder for this preprint (which was not certified by peer review) is the author/funder, who has granted bioRxiv a license to display the preprint in perpetuity. It is made available under aCC-BY-ND 4.0 International license.

FIGURE 3 Loss of SID2/ICS1 or EDS1 abolishes enhanced basal immunity but not growth deficiencies of ipk1-1 or itpk1-2 plants. (a) Growth phenotypes of 3 week-old Col-0, ipk1-1, itpk1-2, ipk1-1 eds1-2, ipk1-1 sid2-1, itpk1-2 eds1-2, itpk1-2 sid2-1, sid2-1, and eds12 plants. (b) Relative expression of $P R 1$ in the indicated plants. qRT-PCR was performed on cDNAs generated from above plants. As an internal control, $M O N 1$ gene expression was used. Expressions are presented as mean $\pm \mathrm{SD}(\mathrm{n}=3)$. (c) PstDC3000 growth assays on eds $1-2$ or sid2-1 combinatorial mutants with ipk1-1 or itpk1-2. Pathogenesis assays were performed and quantified as earlier. Statistical significance shown with different letters is according to posthoc Tukey's test $(\mathrm{p}<0.05)$. (d) Incorporating eds $1-2$ does not change the InsP profiles of ipk11. SAX-HPLC profiles of Tritium-labeled InsPs in Col-0, ipk1-1, eds1-2, and ipk1-1 eds1-2 extracts are shown. Labeling was performed on 3-week-old plants and activities determined by scintillation counts of fractions containing $\mathrm{Ins}_{2}-\mathrm{Ins}_{8}$.

FIGURE 4 Enhanced basal defenses but not phenotypic growth defects in ipk1-1 or itpk1-2 are partially PHR1/PHL1-dependent. (a) Growth phenotypes of 3 week-old Col-0, ipk1-1, itpk1-2, ipk1-1 phrl phl1, itpk1-2 phrl phl1, and phrl phll plants. (b) Introducing phrl phl1 mutations dampen elevated PR1/PR2 expressions in ipk1-1 or itpkl-2. (c) Elevated endogenous $\mathrm{Pi}$, or (d) heightened SPX1 or WRKY38 expression in ipk1-1 or itpk1-2 are downregulated by eds1-2 or sid2-1 mutation. qRT-PCR are normalized to expression of the internal control MON1 gene. All data presented here are mean values \pm SD of three biological and technical replicates $(n=3)$. Different letters indicate differences according to post-hoc Tukey's test $(\mathrm{p}<0.05)$. 
bioRxiv preprint doi: https://doi.org/10.1101/2021.01.27.428180; this version posted January 28,2021 . The copyright holder for this preprint (which was not certified by peer review) is the author/funder, who has granted bioRxiv a license to display the preprint in perpetuity. It is made available under aCC-BY-ND 4.0 International license.

FIGURE 5 SA application induces PSI-gene expressions. SA elevations associate with PSR although defense-gene expressions are suppressed. Kinetics of (a) $P R 1, S P X 1$, or WRKY38 expressions post-SA-treatment on Col-0. Approximately, 3-4 week-old Col-0 plants were spray-treated with SA and samples harvested at indicated time points (mpt, minutes posttreatment) and processed for qRT-PCR analysis. (b) Free SA and total SA+SAG levels in Col0 under Pi-sufficient (625 $\mu \mathrm{M}$-Pi), Pi-deprived (10 $\mu \mathrm{M}-\mathrm{Pi})$, or Pi-replenished post-starvation (10-625 $\mu \mathrm{M}-\mathrm{Pi}$ ) conditions. (c) Relative expression levels of PRI or FRK1 genes under Pisufficient or Pi-deprived growth. For these assays, Col-0 seedlings grown for 14-days under Pi-sufficient conditions were subjected for 4-days to Pi-starvation and then re-supplemented with replete Pi levels for $12 \mathrm{hrs}$, before being processed. The qRT-PCR data are normalized MON1 gene expressions. All data shown here are mean values $( \pm \mathrm{SD}, \mathrm{n}=3)$ with Student's $t$ test for statistical analysis $\left(* * \mathrm{p}<0.001, * * * \mathrm{p}<0.0001,{ }^{* * * *} \mathrm{p}<0.00001\right)$.

FIGURE 6 PHR1 modulates induction of defense gene expressions during basal immunity. Relative expression levels of (a) SID2/ICS1, (b) PR1, (c) PHT3;2, (d) PAP17 in Col-0 and phr1 plants challenged with PstDC3000 at 3dpi (days post-infection). Expression levels are normalized to MON1 and reported as fold change relative to Col-0 (e) Changes in endogenous Pi levels in Col-0 and phrl plants at 3dpi. Data shown here are mean values $\left(_{+}\right.$ $\mathrm{SD}, \mathrm{n}=3)$. Statistical significance is with Student's $t$-test $\left(* * p<0.001,{ }^{* * *} p<0.0001, * * * *\right.$ $p<0.00001$ ). (f) Kinetics of IPK1 and ITPK1 protein levels after PstDC3000 infections at indicated time-points (hours post-infection, hpi). Immunoblots were performed with anti-GFP (for ITPK1-GFP) or anti-Myc (for Myc-IPK1) antibodies. PonceauS staining of the membranes denote comparable protein loadings. 


\section{REFERENCES}

Achary, V. M. M., Ram, B., Manna, M., Datta, D., Bhatt, A., Reddy, M. K., et al. (2017) Phosphite: a novel $P$ fertilizer for weed management and pathogen control. Plant Biotechnol J, 15, 14931508.

Adepoju, O., Williams, S. P., Craige, B., Cridland, C. A., Sharpe, A. K., Brown, A. M., et al. (2019) Inositol Trisphosphate Kinase and Diphosphoinositol Pentakisphosphate Kinase Enzymes Constitute the Inositol Pyrophosphate Synthesis Pathway in Plants. bioRxiv, 724914.

Andersson, M. X., Kourtchenko, O., Dangl, J. L., Mackey, D. and Ellerström, M. (2006) Phospholipasedependent signalling during the AvrRpm1- and AvrRpt2-induced disease resistance responses in Arabidopsis thaliana. Plant J, 47, 947-959.

Azevedo, C. and Saiardi, A. (2006) Extraction and analysis of soluble inositol polyphosphates from yeast. Nature Protocols, 1, 2416-2422.

Baek, D., Chun, H. J., Yun, D. J. and Kim, M. C. (2017) Cross-talk between Phosphate Starvation and Other Environmental Stress Signaling Pathways in Plants. Mol Cells, 40, 697-705.

Berridge, M. J. (1993) Inositol trisphosphate and calcium signalling. Nature, 361, 315-325.

Bhattacharjee, S., Halane, M. K., Kim, S. H. and Gassmann, W. (2011) Pathogen Effectors Target Arabidopsis EDS1 and Alter Its Interactions with Immune Regulators. Science (New York, N.Y.), 334, 1405-1408.

Bigeard, J., Colcombet, J. and Hirt, H. (2015) Signaling Mechanisms in Pattern-Triggered Immunity (PTI). Molecular Plant, 8, 521-539.

Boss, W. F. and Im, Y. J. (2012) Phosphoinositide signaling. Annu Rev Plant Biol, 63, 409-429.

Bustos, R., Castrillo, G., Linhares, F., Puga, M. I., Rubio, V., Pérez-Pérez, J., et al. (2010) A Central Regulatory System Largely Controls Transcriptional Activation and Repression Responses to Phosphate Starvation in Arabidopsis. PLOS Genetics, 6, e1001102.

Caarls, L., Pieterse, C. M. and Van Wees, S. C. (2015) How salicylic acid takes transcriptional control over jasmonic acid signaling. Front Plant Sci, 6, 170.

Cao, H., Glazebrook, J., Clarke, J. D., Volko, S. and Dong, X. (1997) The Arabidopsis NPR1 Gene That Controls Systemic Acquired Resistance Encodes a Novel Protein Containing Ankyrin Repeats. Cell, 88, 57-63.

Castrillo, G., Teixeira, P. J., Paredes, S. H., Law, T. F., de Lorenzo, L., Feltcher, M. E., et al. (2017) Root microbiota drive direct integration of phosphate stress and immunity. Nature, 543, 513-518.

Chiou, T.-J., Aung, K., Lin, S.-I., Wu, C.-C., Chiang, S.-F. and Su, C.-I. (2006) Regulation of Phosphate Homeostasis by MicroRNA in Arabidopsis. The Plant Cell, 18, 412-421.

Cui, H., Gobbato, E., Kracher, B., Qiu, J., Bautor, J. and Parker, J. E. (2017) A core function of EDS1 with PAD4 is to protect the salicylic acid defense sector in Arabidopsis immunity. The New phytologist, 213, 1802-1817.

Cui, H., Tsuda, K. and Parker, J. E. (2015) Effector-Triggered Immunity: From Pathogen Perception to Robust Defense. Annual Review of Plant Biology, 66, 487-511.

DeFraia, C. T., Schmelz, E. A. and Mou, Z. (2008) A rapid biosensor-based method for quantification of free and glucose-conjugated salicylic acid. Plant Methods, 4, 28.

Desai, M., Rangarajan, P., Donahue, J. L., Williams, S. P., Land, E. S., Mandal, M. K., et al. (2014) Two inositol hexakisphosphate kinases drive inositol pyrophosphate synthesis in plants. Plant J, 80, 642-653.

Desfougeres, Y., Wilson, M. S. C., Laha, D., Miller, G. J. and Saiardi, A. (2019) ITPK1 mediates the lipidindependent synthesis of inositol phosphates controlled by metabolism. Proc Natl Acad Sci U $S A, 116,24551-24561$.

Dieck, C. B., Boss, W. F. and Perera, I. Y. (2012) A role for phosphoinositides in regulating plant nuclear functions. Front Plant Sci, 3, 50. 
Dnyaneshwar Ingole, K., Kasera, M., van den Burg, H. A. and Bhattacharjee, S. (2020) Contrasting functions of Arabidopsis SUMO1/2 isoforms with SUMO3 intersect to modulate innate immunity and global SUMOylome responses. bioRxiv, 2020.2005.2015.097535.

Dohmann, E. M., Levesque, M. P., Isono, E., Schmid, M. and Schwechheimer, C. (2008) Auxin responses in mutants of the Arabidopsis CONSTITUTIVE PHOTOMORPHOGENIC9 signalosome. Plant Physiol, 147, 1369-1379.

Donahue, J. L., Alford, S. R., Torabinejad, J., Kerwin, R. E., Nourbakhsh, A., Ray, W. K., et al. (2010) The Arabidopsis thaliana Myo-inositol 1-phosphate synthase1 gene is required for Myo-inositol synthesis and suppression of cell death. Plant Cell, 22, 888-903.

Dong, J., Ma, G., Sui, L., Wei, M., Satheesh, V., Zhang, R., et al. (2019) Inositol Pyrophosphate InsP(8) Acts as an Intracellular Phosphate Signal in Arabidopsis. Mol Plant, 12, 1463-1473.

Feys, B. J., Moisan, L. J., Newman, M.-A. and Parker, J. E. (2001) Direct interaction between the Arabidopsis disease resistance signaling proteins, EDS1 and PAD4. The EMBO journal, 20, 5400-5411.

Garcia, A. V., Blanvillain-Baufume, S., Huibers, R. P., Wiermer, M., Li, G., Gobbato, E., et al. (2010) Balanced nuclear and cytoplasmic activities of EDS1 are required for a complete plant innate immune response. PLoS Pathog, 6, e1000970.

Gil-Mascarell, R., López-Coronado, J. M., Bellés, J. M., Serrano, R. and Rodríguez, P. L. (1999) The Arabidopsis HAL2 -like gene family includes a novel sodium-sensitive phosphatase. The Plant Journal, 17, 373-383.

Gillaspy, G. E. (2011) The cellular language of myo-inositol signaling. The New phytologist, 192, 823839.

Gillaspy, G. E. (2013) The role of phosphoinositides and inositol phosphates in plant cell signaling. Advances in experimental medicine and biology, 991, 141-157.

Gou, M., Shi, Z., Zhu, Y., Bao, Z., Wang, G. and Hua, J. (2012) The F-box protein CPR1/CPR30 negatively regulates R protein SNC1 accumulation. Plant J, 69, 411-420.

Heilmann, I. (2016) Phosphoinositide signaling in plant development. Development, 143, 2044-2055.

Hind, S. R., Pulliam, S. E., Veronese, P., Shantharaj, D., Nazir, A., Jacobs, N. S., et al. (2011) The COP9 signalosome controls jasmonic acid synthesis and plant responses to herbivory and pathogens. Plant J, 65, 480-491.

Hong, Y., Zhao, J., Guo, L., Kim, S. C., Deng, X., Wang, G., et al. (2016) Plant phospholipases D and C and their diverse functions in stress responses. Progress in lipid research, 62, 55-74.

Hung, C. Y., Aspesi, P., Jr., Hunter, M. R., Lomax, A. W. and Perera, I. Y. (2014) Phosphoinositidesignaling is one component of a robust plant defense response. Front Plant Sci, 5, 267.

Jain, R. (2015) Reduction of phytate by down-regulation of Arabidopsis thaliana MIPS and IPK1 genes alters susceptibility to beet cyst nematodes. Nematology, 17, 401-407.

Jones, J. D. and Dangl, J. L. (2006) The plant immune system. Nature, 444, 323-329.

Kim, K. C., Lai, Z., Fan, B. and Chen, Z. (2008) Arabidopsis WRKY38 and WRKY62 transcription factors interact with histone deacetylase 19 in basal defense. Plant Cell, 20, 2357-2371.

Kim, S. I. and Tai, T. H. (2011) Identification of genes necessary for wild-type levels of seed phytic acid in Arabidopsis thaliana using a reverse genetics approach. Mol Genet Genomics, 286, 119-133.

Kinkema, M., Fan, W. and Dong, X. (2000) Nuclear Localization of NPR1 Is Required for Activation of PR Gene Expression. The Plant Cell, 12, 2339-2350.

Krinke, O., Ruelland, E., Valentová, O., Vergnolle, C., Renou, J.-P., Taconnat, L., et al. (2007) Phosphatidylinositol 4-Kinase Activation Is an Early Response to Salicylic Acid in Arabidopsis Suspension Cells. Plant Physiology, 144, 1347-1359.

Kuo, H. F., Chang, T. Y., Chiang, S. F., Wang, W. D., Charng, Y. Y. and Chiou, T. J. (2014) Arabidopsis inositol pentakisphosphate 2-kinase, AtIPK1, is required for growth and modulates phosphate homeostasis at the transcriptional level. Plant J, 80, 503-515. 
Kuo, H. F., Hsu, Y. Y., Lin, W. C., Chen, K. Y., Munnik, T., Brearley, C. A., et al. (2018) Arabidopsis inositol phosphate kinases IPK1 and ITPK1 constitute a metabolic pathway in maintaining phosphate homeostasis. Plant J.

Laha, D., Johnen, P., Azevedo, C., Dynowski, M., Weiss, M., Capolicchio, S., et al. (2015) VIH2 Regulates the Synthesis of Inositol Pyrophosphate InsP $\mathrm{P}_{8}$ and Jasmonate-Dependent Defenses in Arabidopsis. Plant Cell, 27, 1082-1097.

Laha, D., Parvin, N., Hofer, A., Giehl, R. F. H., Fernandez-Rebollo, N., von Wirén, N., et al. (2019) Arabidopsis ITPK1 and ITPK2 Have an Evolutionarily Conserved Phytic Acid Kinase Activity. ACS Chemical Biology, 14, 2127-2133.

Laha, N. P., Dhir, Y. W., Giehl, R. F. H., Schäfer, E. M., Gaugler, P., Shishavan, Z. H., et al. (2020) ITPK1Dependent Inositol Polyphosphates Regulate Auxin Responses in Arabidopsis thaliana. bioRxiv, 2020.2004.2023.058487.

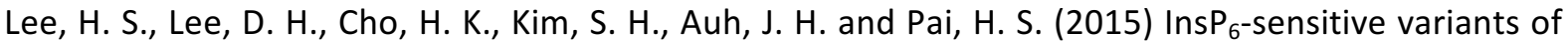
the Gle1 mRNA export factor rescue growth and fertility defects of the ipk1 low-phytic-acid mutation in Arabidopsis. Plant Cell, 27, 417-431.

Lee, Y., Choi, Y. B., Suh, S., Lee, J., Assmann, S. M., Joe, C. O., et al. (1996) Abscisic Acid-Induced Phosphoinositide Turnover in Guard Cell Protoplasts of Vicia faba. Plant Physiology, 110, $987-$ 996.

Lemtiri-Chlieh, F., MacRobbie, E. A., Webb, A. A., Manison, N. F., Brownlee, C., Skepper, J. N., et al. (2003) Inositol hexakisphosphate mobilizes an endomembrane store of calcium in guard cells. Proceedings of the National Academy of Sciences of the United States of America, 100, 1009110095.

Li, Y., Li, S., Bi, D., Cheng, Y. T., Li, X. and Zhang, Y. (2010) SRFR1 Negatively Regulates Plant NB-LRR Resistance Protein Accumulation to Prevent Autoimmunity. PLOS Pathogens, 6, e1001111.

Ma, Y., Zhao, Y. and Berkowitz, G. A. (2017) Intracellular $\mathrm{Ca}^{2+}$ is important for flagellin-triggered defense in Arabidopsis and involves inositol polyphosphate signaling. J Exp Bot, 68, 36173628.

Majerus, P. W. (1992) INOSITOL PHOSPHATE BIOCHEMISTRY. Annual Review of Biochemistry, 61, 225250.

Mishkind, M., Vermeer, J. E., Darwish, E. and Munnik, T. (2009) Heat stress activates phospholipase D and triggers PIP accumulation at the plasma membrane and nucleus. Plant J, 60, 10-21.

Miura, K., Lee, J., Gong, Q., Ma, S., Jin, J. B., Yoo, C. Y., et al. (2011) SIZ1 regulation of phosphate starvation-induced root architecture remodeling involves the control of auxin accumulation. Plant Physiol, 155, 1000-1012.

Monserrate, J. P. and York, J. D. (2010) Inositol phosphate synthesis and the nuclear processes they affect. Current opinion in cell biology, 22, 365-373.

Mosblech, A., Thurow, C., Gatz, C., Feussner, I. and Heilmann, I. (2011) Jasmonic acid perception by COI1 involves inositol polyphosphates in Arabidopsis thaliana. Plant J, 65, 949-957.

Munnik, T. and Nielsen, E. (2011) Green light for polyphosphoinositide signals in plants. Curr Opin Plant Biol, 14, 489-497.

Murphy, A. M., Otto, B., Brearley, C. A., Carr, J. P. and Hanke, D. E. (2008) A role for inositol hexakisphosphate in the maintenance of basal resistance to plant pathogens. Plant J, 56, 638652.

Murthy, P. P. N. (1996) Inositol Phosphates and Their Metabolism in Plants. In: myo-Inositol Phosphates, Phosphoinositides, and Signal Transduction. (Biswas, B. B. and Biswas, S., eds.). Boston, MA: Springer US, pp. 227-255.

Navarro, L., Dunoyer, P., Jay, F., Arnold, B., Dharmasiri, N., Estelle, M., et al. (2006) A plant miRNA contributes to antibacterial resistance by repressing auxin signaling. Science (New York, N.Y.), 312, 436-439. 
Nawrath, C. and Métraux, J.-P. (1999) Salicylic Acid Induction-Deficient Mutants of Arabidopsis Express $P R-2$ and $P R-5$ and Accumulate High Levels of Camalexin after Pathogen Inoculation. The Plant Cell, 11, 1393-1404.

Poon, J. S. Y., Le Fevre, R. E., Carr, J. P., Hanke, D. E. and Murphy, A. M. (2020) Inositol hexakisphosphate biosynthesis underpins PAMP-triggered immunity to Pseudomonas syringae pv. tomato in Arabidopsis thaliana but is dispensable for establishment of systemic acquired resistance. Mol Plant Pathol, 21, 376-387.

Puga, M. I., Mateos, I., Charukesi, R., Wang, Z., Franco-Zorrilla, J. M., de Lorenzo, L., et al. (2014) SPX1 is a phosphate-dependent inhibitor of Phosphate Starvation Response 1 in Arabidopsis. Proc Natl Acad Sci U S A, 111, 14947-14952.

Ramírez, V., Van der Ent, S., García-Andrade, J., Coego, A., Pieterse, C. M. J. and Vera, P. (2010) OCP3 is an important modulator of NPR1-mediated jasmonic acid-dependent induced defenses in Arabidopsis. BMC Plant Biology, 10, 199.

Ried, M. K., Wild, R., Zhu, J., Broger, L., Harmel, R. K., Hothorn, L. A., et al. (2019) Inositol pyrophosphates promote the interaction of SPX domains with the coiled-coil motif of PHR transcription factors to regulate plant phosphate homeostasis. bioRxiv, 2019.2012.2013.875393.

Riemer, E., Laha, D., Harmel, R. K., Gaugler, P., Pries, V., Frei, M., et al. (2020) ITPK1 is an InsP 6 /ADP phosphotransferase that controls systemic phosphate homeostasis in Arabidopsis. bioRxiv, 2020.2005.2018.100297.

Ruan, W., Guo, M., Wang, X., Guo, Z., Xu, Z., Xu, L., et al. (2019) Two RING-Finger Ubiquitin E3 Ligases Regulate the Degradation of SPX4, An Internal Phosphate Sensor, for Phosphate Homeostasis and Signaling in Rice. Mol Plant, 12, 1060-1074.

Sardar, A., Nandi, A. K. and Chattopadhyay, D. (2017) CBL-interacting protein kinase 6 negatively regulates immune response to Pseudomonas syringae in Arabidopsis. Journal of experimental botany, 68, 3573-3584.

Schenk, S. T. and Schikora, A. (2015) Staining of Callose Depositions in Root and Leaf Tissues. Bioprotocol, 5, e1429.

Schwessinger, B. and Ronald, P. C. (2012) Plant Innate Immunity: Perception of Conserved Microbial Signatures. Annual Review of Plant Biology, 63, 451-482.

Seybold, H., Trempel, F., Ranf, S., Scheel, D., Romeis, T. and Lee, J. (2014) $\mathrm{Ca}^{2+}$ signalling in plant immune response: from pattern recognition receptors to $\mathrm{Ca} 2+$ decoding mechanisms. New Phytologist, 204, 782-790.

Sheard, L. B., Tan, X., Mao, H., Withers, J., Ben-Nissan, G., Hinds, T. R., et al. (2010) Jasmonate perception by inositol-phosphate-potentiated COI1-JAZ co-receptor. Nature, 468, 400-405.

Shears, S. B., Ganapathi, S. B., Gokhale, N. A., Schenk, T. M. H., Wang, H., Weaver, J. D., et al. (2012) Defining signal transduction by inositol phosphates. Subcell Biochem, 59, 389-412.

Shen, M., Lim, C. J., Park, J., Kim, J. E., Baek, D., Nam, J., et al. (2020) HOS15 is a transcriptional corepressor of NPR1-mediated gene activation of plant immunity. Proceedings of the National Academy of Sciences, 202016049.

Shi, J., Wang, H., Hazebroek, J., Ertl, D. S. and Harp, T. (2005) The maize low-phytic acid 3 encodes a myo-inositol kinase that plays a role in phytic acid biosynthesis in developing seeds. Plant $J$, 42, 708-719.

Silva, E. O. and Bracarense, A. P. (2016) Phytic Acid: From Antinutritional to Multiple Protection Factor of Organic Systems. J Food Sci, 81, R1357-1362.

Spoel, S. H., Mou, Z., Tada, Y., Spivey, N. W., Genschik, P. and Dong, X. (2009) Proteasome-mediated turnover of the transcription coactivator NPR1 plays dual roles in regulating plant immunity. Cell, 137, 860-872.

Staxen, I., Pical, C., Montgomery, L. T., Gray, J. E., Hetherington, A. M. and McAinsh, M. R. (1999) Abscisic acid induces oscillations in guard-cell cytosolic free calcium that involve 
phosphoinositide-specific phospholipase C. Proceedings of the National Academy of Sciences of the United States of America, 96, 1779-1784.

Stevenson-Paulik, J., Bastidas, R. J., Chiou, S. T., Frye, R. A. and York, J. D. (2005) Generation of phytatefree seeds in Arabidopsis through disruption of inositol polyphosphate kinases. Proc Natl Acad Sci U S A, 102, 12612-12617.

Sweetman, D., Stavridou, I., Johnson, S., Green, P., Caddick, S. E. and Brearley, C. A. (2007) Arabidopsis thaliana inositol 1,3,4-trisphosphate 5/6-kinase 4 (AtITPK4) is an outlier to a family of ATPgrasp fold proteins from Arabidopsis. FEBS Lett, 581, 4165-4171.

Tan, X., Calderon-Villalobos, L. I., Sharon, M., Zheng, C., Robinson, C. V., Estelle, M., et al. (2007) Mechanism of auxin perception by the TIR1 ubiquitin ligase. Nature, 446, 640-645.

Thomma, B. P. H. J., Nürnberger, T. and Joosten, M. H. A. J. (2011) Of PAMPs and Effectors: The Blurred PTI-ETI Dichotomy. The Plant Cell, 23, 4-15.

Turner, B. L., Papházy, M. J., Haygarth, P. M. and Mckelvie, I. D. (2002) Inositol phosphates in the environment. Philosophical Transactions of the Royal Society of London. Series B: Biological Sciences, 357, 449-469.

van Wersch, R., Li, X. and Zhang, Y. (2016) Mighty Dwarfs: Arabidopsis Autoimmune Mutants and Their Usages in Genetic Dissection of Plant Immunity. Front Plant Sci, 7, 1717.

Varadarajan, D. K., Karthikeyan, A. S., Matilda, P. D. and Raghothama, K. G. (2002) Phosphite, an analog of phosphate, suppresses the coordinated expression of genes under phosphate starvation. Plant Physiol, 129, 1232-1240.

Voigt, C. A. (2014) Callose-mediated resistance to pathogenic intruders in plant defense-related papillae. Front Plant Sci, 5, 168.

Walia, Y., Ingole, K. D., Kasera, M., Peddiraju, S., Laha, D., Schaaf, G., et al. (2020) Arabidopsis inositol polyphosphate kinases regulate COP9 signalosome functions in phosphate-homeostasis. bioRxiv, 2020.2010.2002.323584.

Wang, D., Pajerowska-Mukhtar, K., Culler, A. H. and Dong, X. (2007) Salicylic acid inhibits pathogen growth in plants through repression of the auxin signaling pathway. Curr Biol, 17, 1784-1790.

Whitfield, H., White, G., Sprigg, C., Riley, A. M., Potter, B. V. L., Hemmings, A. M., et al. (2020) An ATPresponsive metabolic cassette comprised of inositol tris/tetrakisphosphate kinase 1 (ITPK1) and inositol pentakisphosphate 2-kinase (IPK1) buffers diphosphosphoinositol phosphate levels. Biochem J, 477, 2621-2638.

Wildermuth, M. C., Dewdney, J., Wu, G. and Ausubel, F. M. (2001) Isochorismate synthase is required to synthesize salicylic acid for plant defence. Nature, 414, 562-565.

Wilson, M. P. and Majerus, P. W. (1997) Characterization of a cDNA Encoding Arabidopsis thaliana Inositol 1,3,4-trisphosphate 5/6-kinase. Biochemical and Biophysical Research Communications, 232, 678-681.

Xia, H. J., Brearley, C., Elge, S., Kaplan, B., Fromm, H. and Mueller-Roeber, B. (2003) Arabidopsis inositol polyphosphate 6-/3-kinase is a nuclear protein that complements a yeast mutant lacking a functional ArgR-Mcm1 transcription complex. Plant Cell, 15, 449-463.

Zhang, Y., Fan, W., Kinkema, M., Li, X. and Dong, X. (1999) Interaction of NPR1 with basic leucine zipper protein transcription factors that bind sequences required for salicylic acid induction of the $P R-1$ gene. Proceedings of the National Academy of Sciences, 96, 6523-6528.

Zheng, X. Y., Spivey, N. W., Zeng, W., Liu, P. P., Fu, Z. Q., Klessig, D. F., et al. (2012) Coronatine promotes Pseudomonas syringae virulence in plants by activating a signaling cascade that inhibits salicylic acid accumulation. Cell Host Microbe, 11, 587-596.

Zhong, Y., Wang, Y., Guo, J., Zhu, X., Shi, J., He, Q., et al. (2018) Rice SPX6 negatively regulates the phosphate starvation response through suppression of the transcription factor PHR2. The New phytologist, 219, 135-148.

Zhu, J., Lau, K., Puschmann, R., Harmel, R. K., Zhang, Y., Pries, V., et al. (2019) Two bifunctional inositol pyrophosphate kinases/phosphatases control plant phosphate homeostasis. eLife, 8, e43582. 
(a)
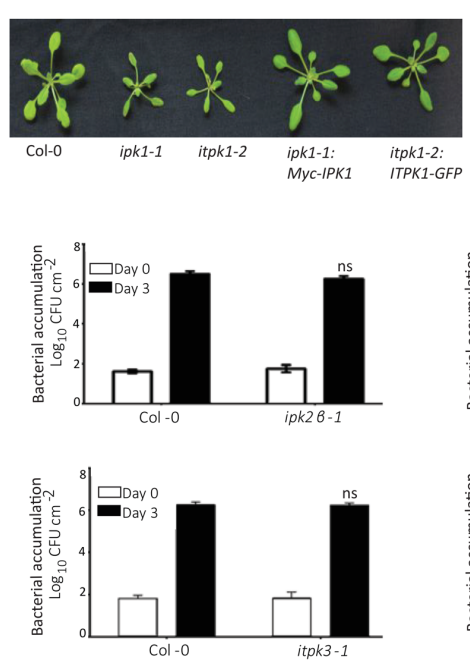

(c) (b)
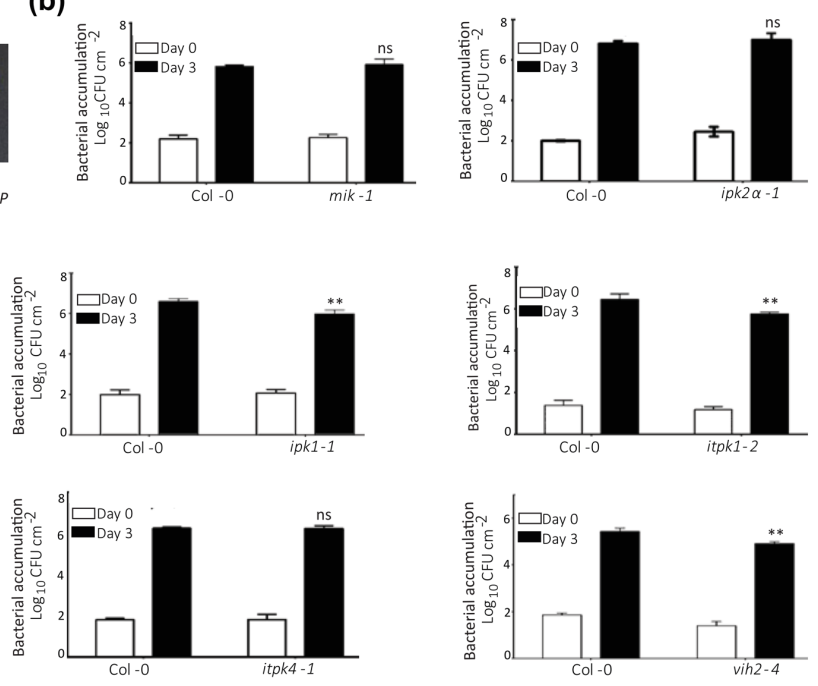

(d)

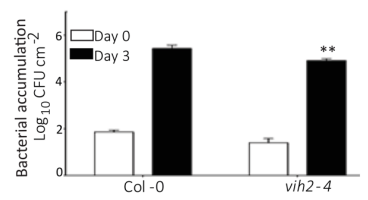

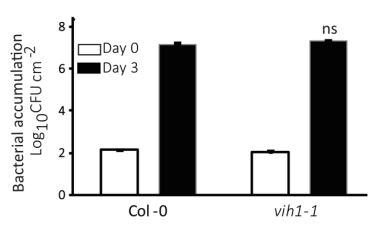
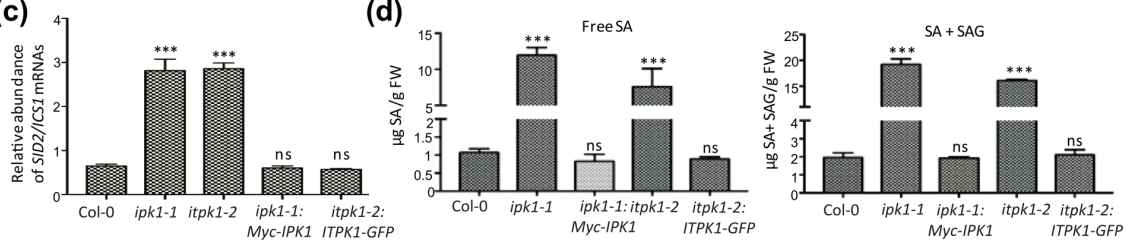

FIGURE 1 Selective Arabidopsis InsP-kinase mutants display enhanced basal defenses against PstDC3000. (a) Growth phenotypes of 3 week-old Col-0, ipk1-1, itpk1-2, and the corresponding complemented lines ipk1-1:Myc-IPK1 and itpk1-2:ITPK1-GFP. (b) PstDC3000 infection assays. Leaves from indicated mutants and Col-0 plants were infiltrated with bacterial suspension at a density of $5 \times 10^{4} \mathrm{cfu} / \mathrm{ml}$. Bacterial inoculum in the infiltrated leaves (Day 0) and its growth (Day 3) were quantified on media plates containing appropriate antibiotics. (c) Relative expression of SID2/ICS1 in the indicated plants. Total RNA was isolated from leaves of 3-4 plants, reverse transcribed, and qRT-PCRs performed. Expressions were normalized to MON1. (d) Endogenous levels of free SA and total SA+SAG in the indicated plants. SA estimations were performed on 3-4week-old plants. Data presented are mean $( \pm \mathrm{SD})$ of three biological and technical replicates. Statistical analysis is according to Student's $t$-test $(* * p<0.001, * * * p<0.0001$, ns $=$ not significant $)$. 
(a)
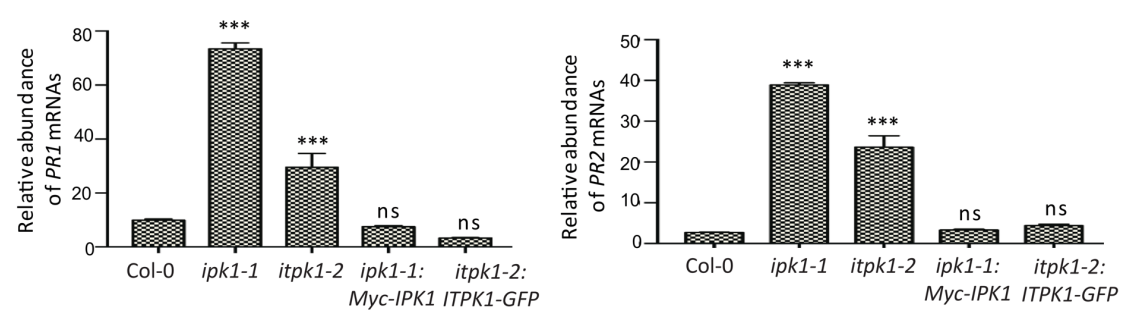

(b)

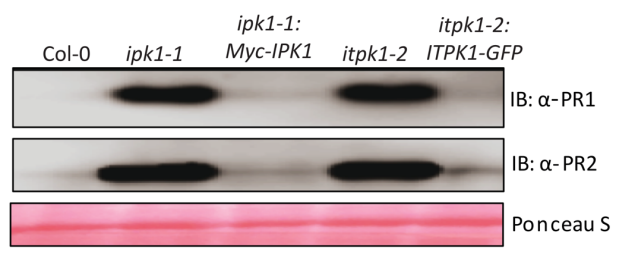

(f)

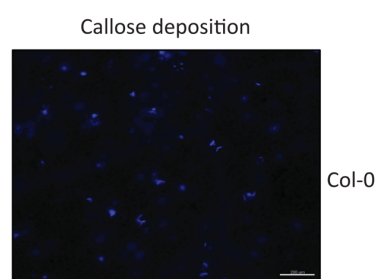

(c)
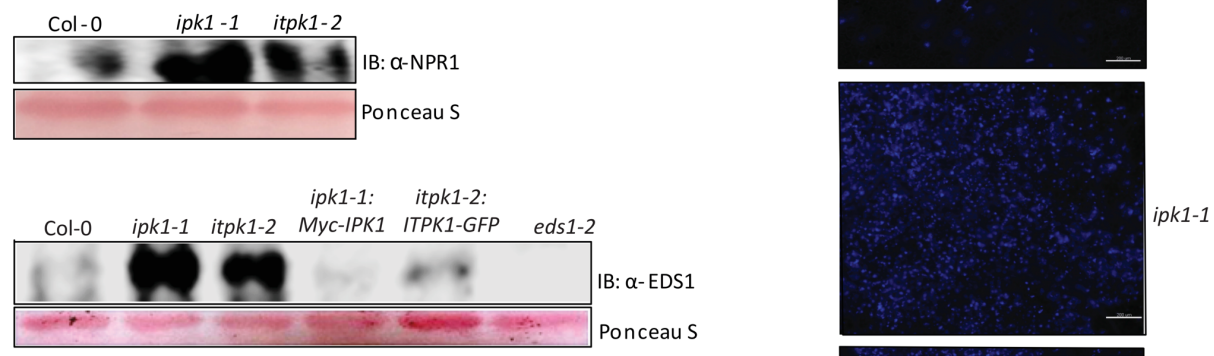

(d)

(e)
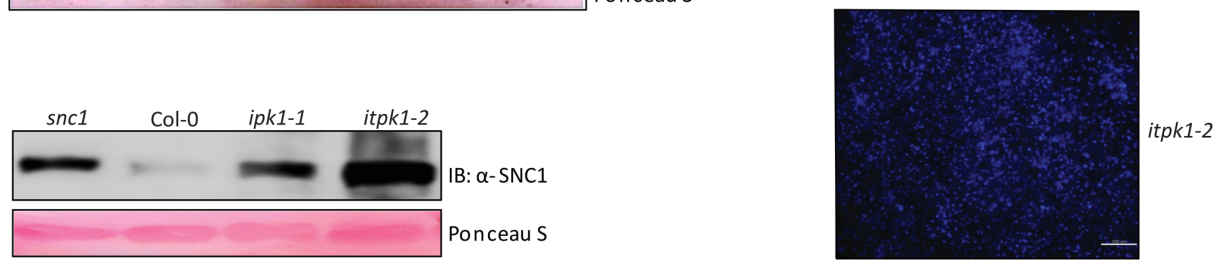

\section{FIGURE 2 Expression of defense-associated genes/proteins are upregulated in ipk1-1}

or itpk1-2 plants. (a) Relative expression of $P R 1$ or $P R 2$ transcripts. qRT-PCRs were performed and normalized to MON1 gene-expressions as an internal control. Values are mean $\pm \mathrm{SD}$ with 3 biological and technical replicates $(n=3)$. Student's $t$-test analysis is shown $(* * * p<0.0001, \mathrm{~ns}=$ not significant). Immunoblots of defense-associated proteins (b) PR1 or PR2, (c) NPR1, (d) EDS1, or (e) R protein SNC1 in indicated plants. Total proteins were probed with respective antibodies. The membrane was stained with Ponceau $\mathrm{S}$ to demonstrate comparable protein loadings. (f) Callose deposits on Col-0, ipk1-1, or itpk1-2 leaves. Fully expanded leaves from 3-week-old plants were stained for callose and observed under a fluorescence microscope. Scale bar $=50 \mu \mathrm{m}$. 
(a)

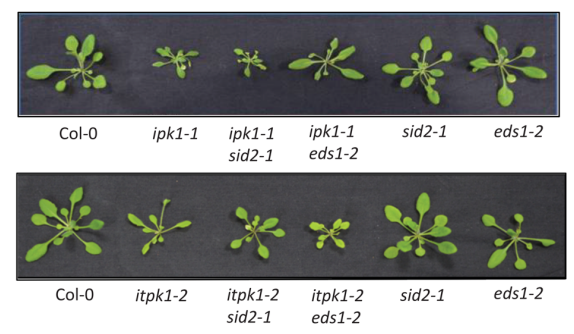

(c)
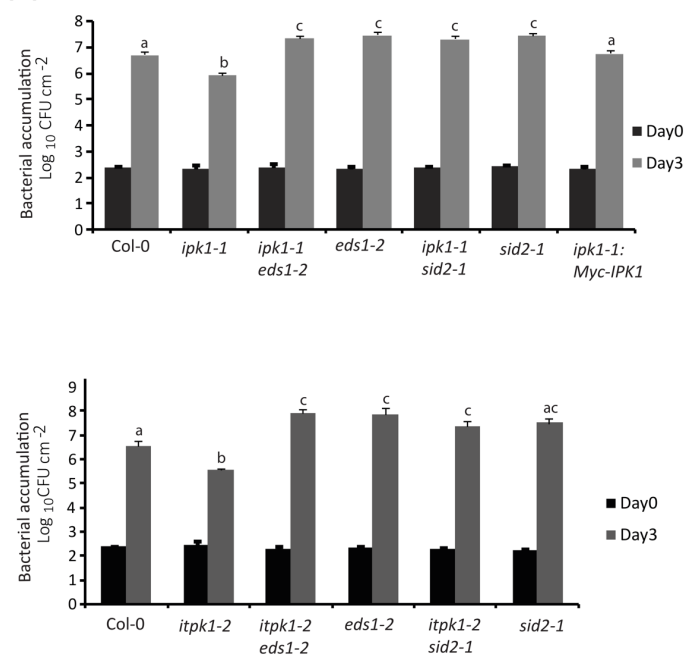

(b)

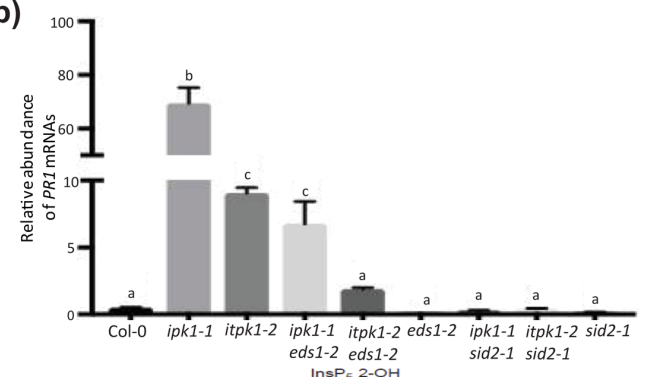

(d)
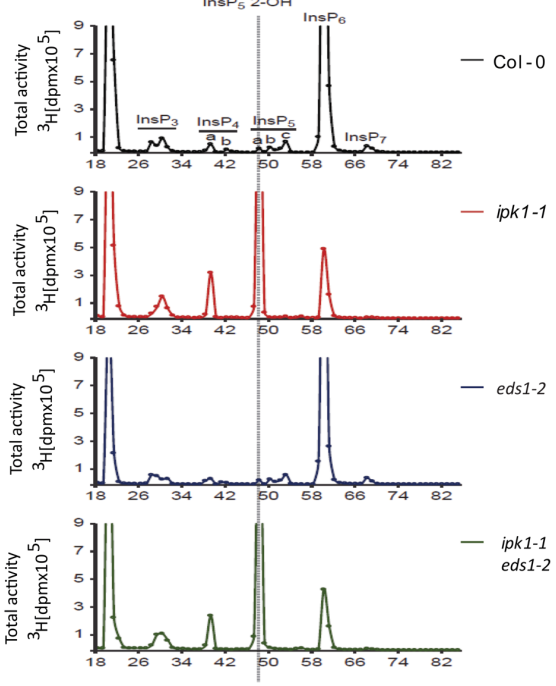

FIGURE 3 Loss of SID2/ICS1 or EDS1 abolishes enhanced basal immunity but not growth deficiencies of ipk1-1 or itpk1-2 plants. (a) Growth phenotypes of 3 week-old Col-0, ipk1-1, itpk1-2, ipk1-1 eds1-2, ipk1-1 sid2-1, itpk1-2 eds1-2, itpk1-2 sid2-1, sid2-1, and eds12 plants. (b) Relative expression of PRI in the indicated plants. qRT-PCR was performed on cDNAs generated from above plants. As an internal control, MON1 gene expression was used. Expressions are presented as mean $\pm \mathrm{SD}(\mathrm{n}=3)$. (c) PstDC3000 growth assays on eds $1-2$ or sid2-1 combinatorial mutants with ipk1-1 or itpk1-2. Pathogenesis assays were performed and quantified as earlier. Statistical significance shown with different letters is according to posthoc Tukey's test $(\mathrm{p}<0.05)$. (d) Incorporating eds 1-2 does not change the InsP profiles of ipk11. SAX-HPLC profiles of Tritium-labeled InsPs in Col-0, ipk1-1, eds1-2, and ipk1-1 eds1-2 extracts are shown. Labeling was performed on 3-week-old plants and activities determined by scintillation counts of fractions containing $\operatorname{Ins}_{2}-\operatorname{Ins}_{8}$. 
(a)

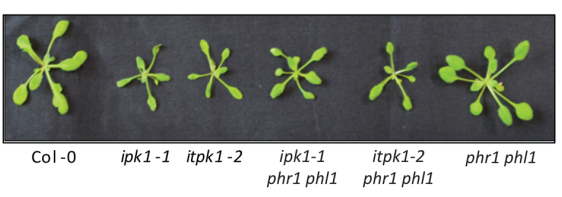

(b)
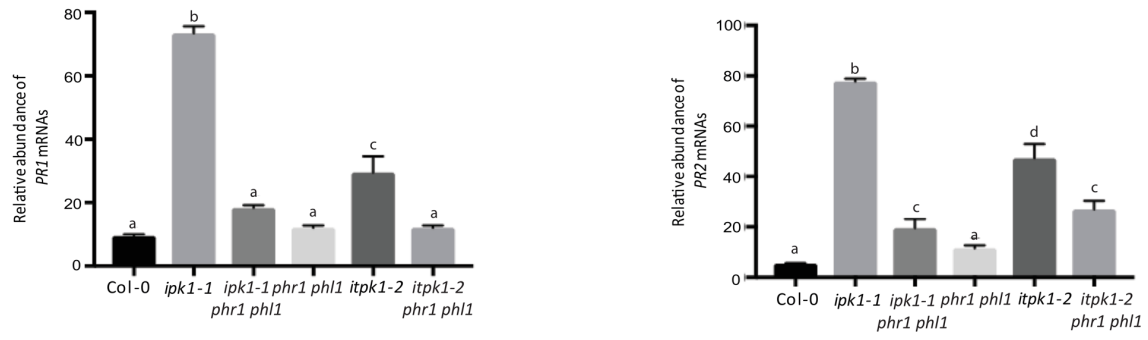

(c)
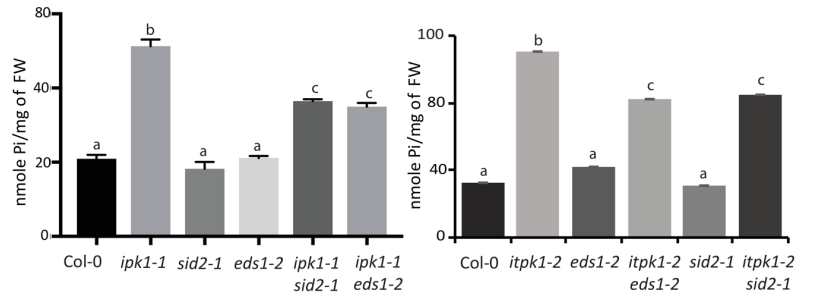

(d)

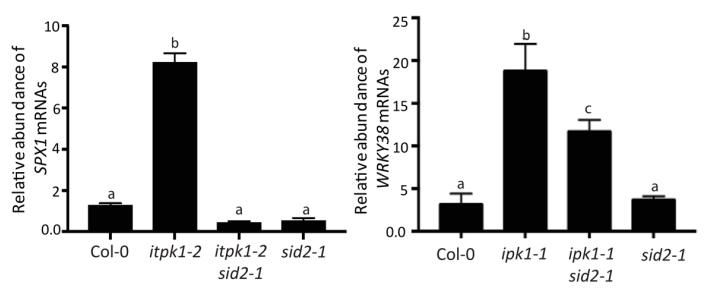

FIGURE 4 Enhanced basal defenses but not phenotypic growth defects in ipk1-1 or itpk1-2 are partially PHR1/PHL1-dependent. (a) Growth phenotypes of 3 week-old Col-0, ipk1-1, itpk1-2, ipk1-1 phr1 phl1, itpk1-2 phrl phl1, and phrl phl1 plants. (b) Introducing phr1 phl1 mutations dampen elevated PR1/PR2 expressions in ipk1-1 or itpkl-2. (c) Elevated endogenous $\mathrm{Pi}$, or (d) heightened SPXI or WRKY38 expression in ipk1-1 or itpk1-2 are downregulated by eds1-2 or sid2-1 mutation. qRT-PCR are normalized to expression of the internal control MON1 gene. All data presented here are mean values $\pm \mathrm{SD}$ of three biological and technical replicates $(n=3)$. Different letters indicate differences according to post-hoc Tukey's test $(\mathrm{p}<0.05)$. 
(a)

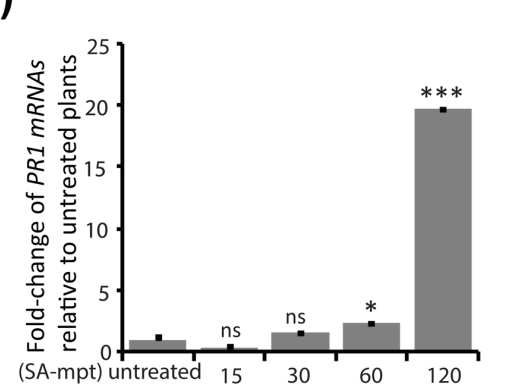

(b)

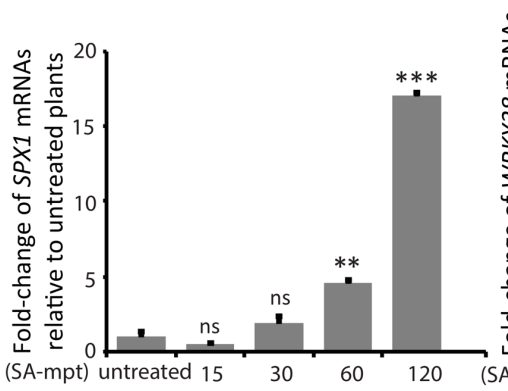

(c)
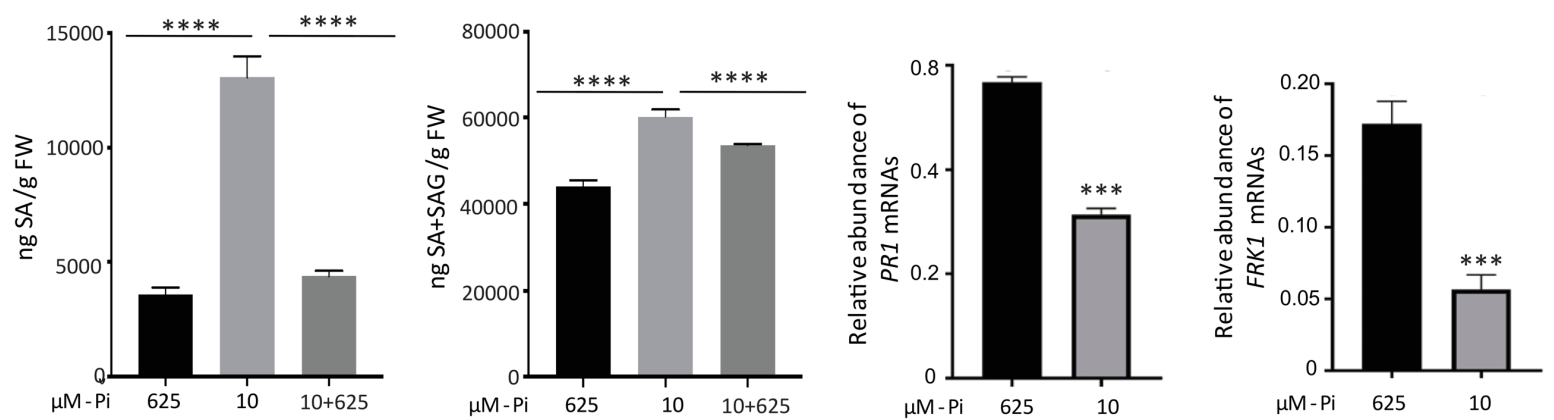

FIGURE 5 SA application induces PSI-gene expressions. SA elevations associate with PSR although defense-gene expressions are suppressed. Kinetics of (a) $P R 1, S P X 1$, or WRKY38 expressions post-SA-treatment on Col-0. Approximately, 3-4 week-old Col-0 plants were spray-treated with SA and samples harvested at indicated time points (mpt, minutes posttreatment) and processed for qRT-PCR analysis. (b) Free SA and total SA+SAG levels in Col0 under Pi-sufficient (625 $\mu \mathrm{M}-\mathrm{Pi})$, Pi-deprived $(10 \mu \mathrm{M}-\mathrm{Pi})$, or Pi-replenished post-starvation (10-625 $\mu \mathrm{M}-\mathrm{Pi}$ ) conditions. (c) Relative expression levels of PR1 or FRK1 genes under Pisufficient or Pi-deprived growth. For these assays, Col-0 seedlings grown for 14-days under Pi-sufficient conditions were subjected for 4-days to Pi-starvation and then re-supplemented with replete Pi levels for $12 \mathrm{hrs}$, before being processed. The qRT-PCR data are normalized MON1 gene expressions. All data shown here are mean values $( \pm \mathrm{SD}, \mathrm{n}=3)$ with Student's $t$ test for statistical analysis $\left(* * \mathrm{p}<0.001,{ }^{* * *} \mathrm{p}<0.0001,{ }^{* * * *} \mathrm{p}<0.00001\right)$. 
(a)

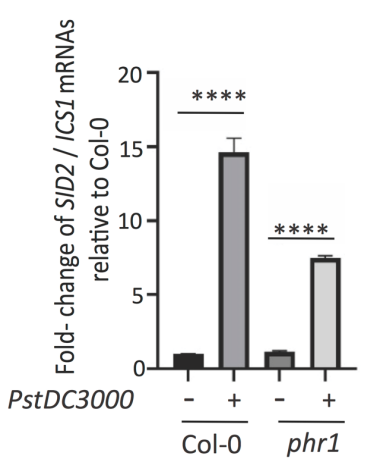

(e)

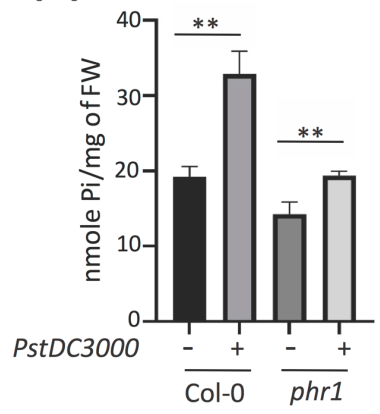

(b)

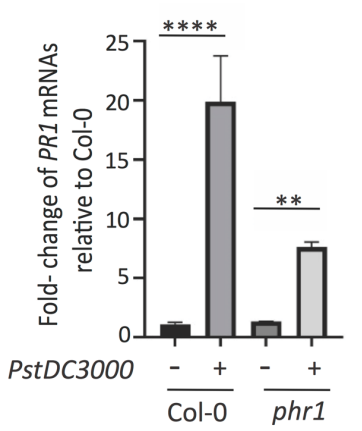

(f) (c)

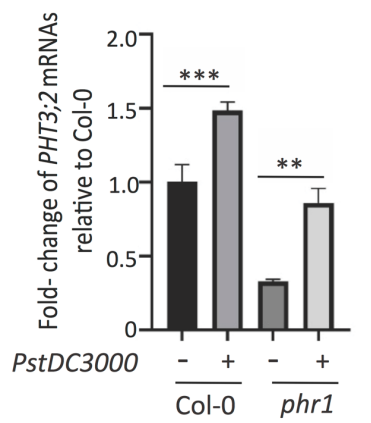

(d)

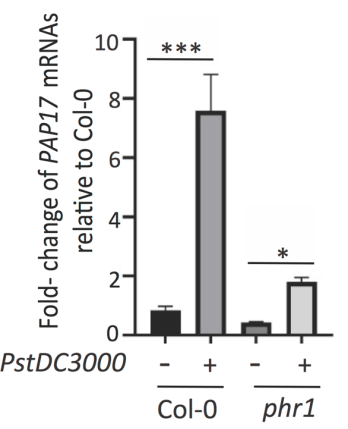

FIGURE 6 PHR1 modulates induction of defense gene expressions during basal immunity. Relative expression levels of (a) SID2/ICS1, (b) PR1, (c) PHT3;2, (d) PAP17 in Col-0 and phr 1 plants challenged with PstDC3000 at 3dpi (days post-infection). Expression levels are normalized to MON1 and reported as fold change relative to Col-0 (e) Changes in endogenous Pi levels in Col-0 and phrl plants at 3dpi. Data shown here are mean values $( \pm$ $\mathrm{SD}, \mathrm{n}=3)$. Statistical significance is with Student's $t$-test $\left(* * p<0.001,{ }^{* * *} p<0.0001,{ }^{* * * *}\right.$ $p<0.00001$ ). (f) Kinetics of IPK1 and ITPK1 protein levels after PstDC3000 infections at indicated time-points (hours post-infection, hpi). Immunoblots were performed with anti-GFP (for ITPK1-GFP) or anti-Myc (for Myc-IPK1) antibodies. PonceauS staining of the membranes denote comparable protein loadings. 